\title{
Cerámica pintada romana de tradición indígena procedente de Bilbilis (Calatayud, Zaragoza)
}

\author{
Rosa aurora luezas Pascual y Manuel Martín-Bueno
}

Las excavaciones arqueológicas que desde 1971 a 1985 se han venido realizando en el Municipium Augusta Bilbilis han proporcionado un conjunto de materiales cerámicos de gran interés, cuyo estudio nos permite conocer gran cantidad de datos referentes al modo de vida, gustos y usos culinarios de sus habitantes.

En este estudio vamos a centrar nuestra atención en uno de esos conjuntos cerámicos, el de la cerámica pintada romana, compuesto por un total de 163 fragmentos, no por su escasez menos representativos.

Este tipo de cerámica hasta el estudio de Abascal (Abascal, 1986), que acuñó el termino de "pintada romana de tradición indigena" ha recibido distintas denominaciones: tardo-celtibérica, de tradición celtibérica, cerámica ibérica, pintada de técnica ibérica, etc.

El interés del estudio de estos materiales viene dado por la pervivencia de una serie de técnicas, tradiciones y decoraciones celtibéricas en época imperial romana, síntoma de la personalidad de ciertos talleres que, frente a la costumbre generalizada de copiar las formas importadas romanas, mantienen las tradiciones netamente peninsulares y afirman su independencia.

Para el estudio de estas cerámicas, de menaje doméstico, hemos seguido una clasificación tipológica, basada no sólo en el estudio morfológico, sino también en el tipo de pasta utilizada en su manufactura.

\section{CARACTERÍSTICAS TÉCNICAS}

La decoración, aplicada con un pincel, ha sido realizada en colores monocromos: rojo vinoso o gris-negro. En cuanto a su situación en la vasija, en las formas abiertas se ubica en la superficie exterior, y a veces en 
la interior (caso de copas, cuencos) y parte superior del borde (copas, orzas o kalathos). En las formas cerradas (botellas o jarras) se localiza en el borde y cuello, parte superior del cuerpo, así como en las asas. Algunas piezas han recibido una ligera aguada o pseudoengobe previamente a la recepción de la pintura.

\section{TIPOS DE PASTAS}

\section{*Pasta 1}

La arcilla se encuentra bastante depurada, sin desgrasante visible a simple vista, presenta un aspecto amarillento-blanquecino (Cailleux M70/71), no muy compacta, más bien deleznable, que mancha al tocarla. La encontramos exclusivamente en las cerámicas «tipo Clunia».

\section{* Pasta 2}

Es una pasta dura y muy compacta, bastante depurada, sin desgrasante visible a simple vista, a excepción de algunos puntitos brillantes. Su color es amarillo-marrón pálido.

\section{*Pasta 3}

Pasta muy dura y compacta, sin desgrasante visible a simple vista. La superficie interior presenta un color gris-pizarra, mientras que la exterior es rojiza, lo que indica una alternancia de atmósferas durante la cocción ("corte en sandwich»). A veces las superficies exteriores se encuentran espatuladas, con un brillo mate y tacto suave. La calidad técnica de la pasta y cochura son admirables. Sonido metálico a la percusión.

\section{*Pasta 4}

Encontramos dos variantes dentro de este tipo de pasta diferenciadas, aunque es posible que análisis fisico-químicos confirmasen que se trata de la misma.

Pasta 4a.- Es de color rojizo, con abundante desgrasante visible en superficie, compuesto por partículas de caliza, puntitos brillantes y presencia de algunas vacuolas.

Pasta 4b.- Presenta un color marrón tostado (Cailleux N-53), salvo en el ejemplar $n^{\circ} 96$ de la Fig. 25 cuya superficie interior es de color rojizo 
(Cailleux N-57), encontrándose bastante depurada, no se aprecia desgrasante a simple vista, a excepción de puntitos brillantes de mica y algunas partículas calizas.

Además de estos cuatro tipos identificados, existen casos aislados de pastas que no pueden incluirse en ninguna de las tres clasificaciones propuestas, constituyendo, por el momento, pastas unitarias.

\section{Decoración}

\section{A) Motivos geométricos}

A.1.- Líneas paralelas horizontales, motivo muy extendido en el mundo indigena, tanto de la Meseta (Valeria, Osuna et alii, 1977; Ercavica, Osuna, 1976) como del litoral ibérico.

A.2.- Líneas paralelas verticales, motivo no tan común como el anterior, pero uno de los más extendidos. A veces las líneas pueden ser oblicuas.

Son uno de los motivos más ampliamente representados en los ejemplares estudiados. Aparecen tanto aisladamente (en cuencos, copas), como combinados con todo tipo de ornamentaciones: geométricas, vegetales, zoomorfas.

Como motivo aislado podemos rastrear su uso ya en la cerámica ibérica, manteniéndose en época alto-imperial, en yacimientos como Libia (Herramélluri, La Rioja) (Marcos Pous, 1979, Fig. 40, no 6420-6421, p. 205; Fig. 41, p. 206), Valeria (Cuenca) (Osuna et alii, 1977, Fig. A-1, C-4, A-4), Ercavica (Cuenca) (Osuna 1976, Figs. 17 a 21), Arcóbriga (Martín, 1992, Fig. $4.7 n^{\circ} 52-53$, p. 187) y perdurando hasta el Bajo-Imperio, combinado con otros motivos (Abascal, 1986, № 786 a 790), o aisladamente, como puede verse en los hallazgos de la villa de Tarancueña (Soria) (Abascal, 1986, Fig. 139, no 743), Complutum (Alcalá de Henares) (Abascal, 1986, Fig. 140, no 745, 746, 748).

A.3.- Líneas onduladas, serpentiformes, normalmente horizontales, típicas de la cerámica celtibérica y prolongadas en época romana. Aunque en la cerámica engobada pintada son muy típicas las líneas onduladas verticales.

Son otro motivo muy frecuente, constituido por agrupaciones de líneas, normalmente horizontales (en cuencos y vasos carenados) o verticales (golletes de botellas o jarras, y orzas), aunque también, y de forma menos 
A
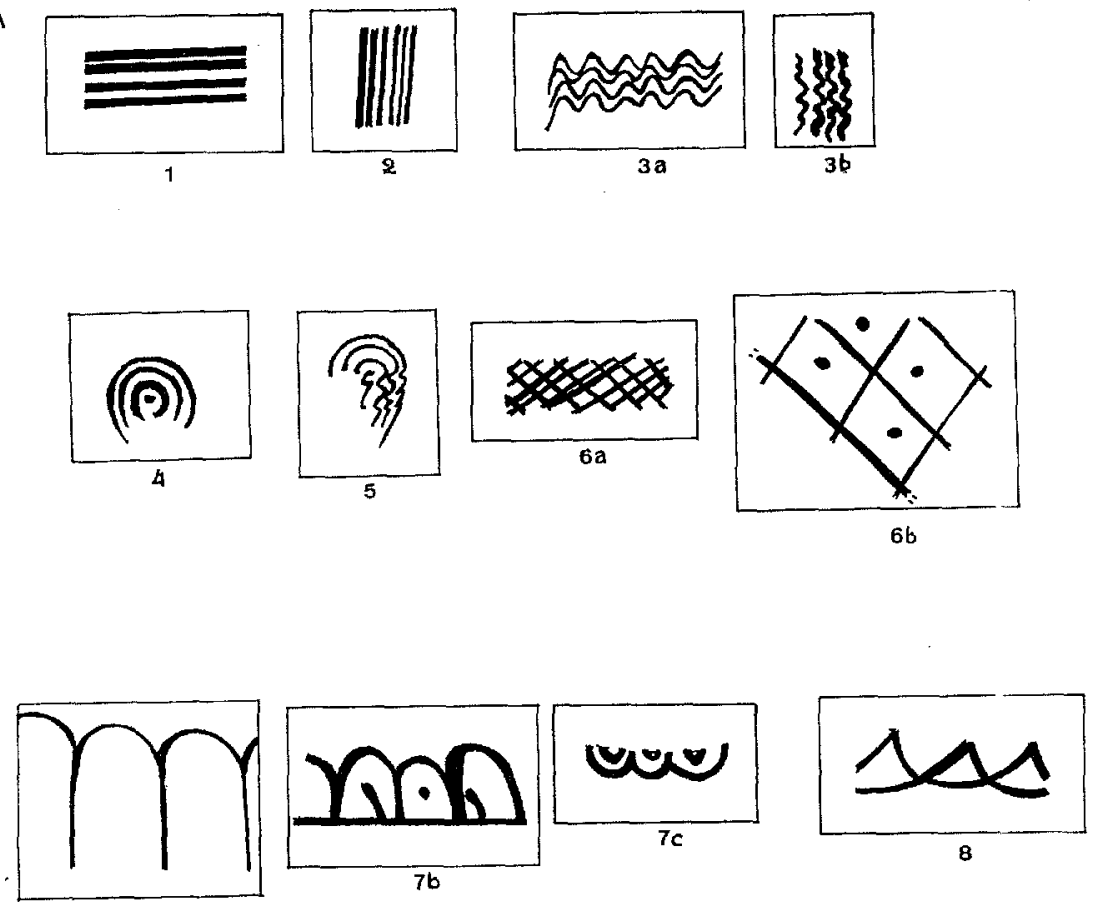

$7 a$
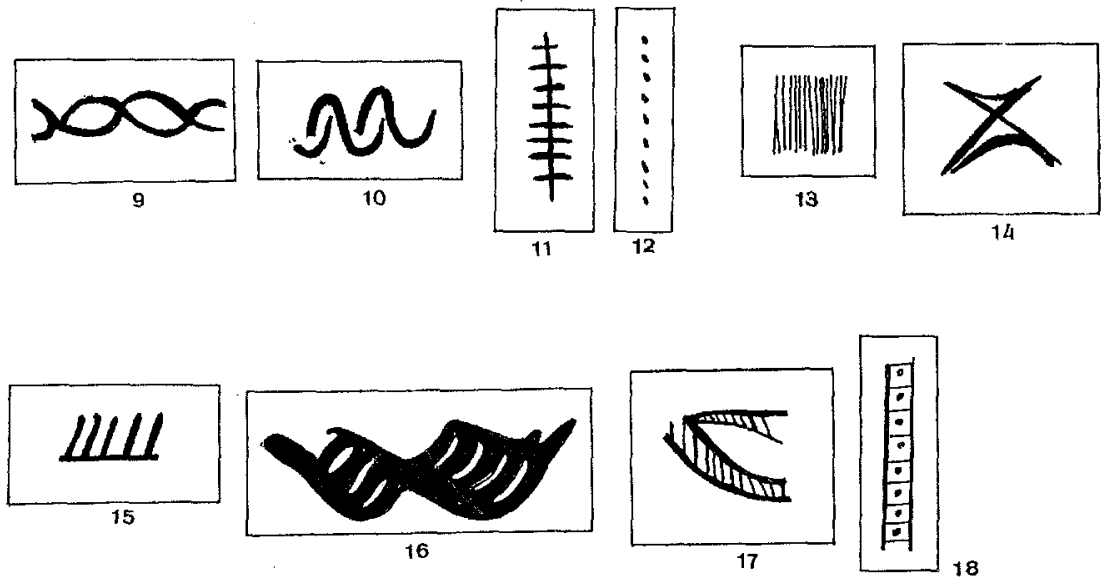
frecuente, aparecen inclinadas. Es muy usual su combinación con los motivos A.4. y A.5.: círculos y semicírculos concéntricos - siendo uno de los motivos más comunes del alfar de Turiaso (Tarazona, Zaragoza) (Amaré, 1984, Lám. VIII) aisladamente o combinados, dando lugar en ocasiones a una fusión de ambos elementos.

Encontramos paralelos de esta decoración, aisladamente, en Clunia (Coruña del Conde, Burgos) (Abascal, 1986, Fig. 25, no 100, 101), Arcóbriga (Monreal de Ariza, Zaragoza) (Martín, 1992, Fig. 4.1. no 10; Fig. 4.2. no 11); Coscojal I (Traibuenas, Rada, Navarra) (Sesma-García, 1994, Fig. 3.12); y combinada en Arcóbriga (Martín, 1992, Fig. 4.1. no 8; Fig. 4.2. $n^{\circ} 13$ a 17)

A.4.- Círculos concéntricos, normalmente realizados con un instrumento geométrico, un compás (así puede comprobarse en la Fig. 18, no 73 , donde se observa un punto central inciso que es la marca dejada por el apoyo del compás), son muy típicos de la ornamentación indígena (Ercavica, Osuna, 1976, Fig. 23), manteniéndose en época alto-imperial, con mucha frecuencia, e incluso perdurando en el Bajo-Imperio (Abascal, 1986, Fig. 164, no 838).

A.5.- - Semicírculos concéntricos, que en la mayoría de los casos parecen estar hechos con un instrumento geométrico - un compás-, a excepción del ejemplar $n^{\circ} 70$ (Fig. 17) en que parecen haber sido trazados a mano alzada. A veces aparecen adosados a una línea contínua, típicos del mundo celtibérico. En otras ocasiones, los semicírculos concéntricos terminan en líneas onduladas verticales paralelas (Fig. 10, no 33 ).

A.6.- Entramado de líneas oblicuas, perpendiculares entre sí o reticulado. A veces alcanzan un gran tamaño y contienen un punto en el interior de cada rombo.

Ejemplares paralelos de la primera variedad tenemos en Libia (Herramélluri, La Rioja) (Marcos Pous, 1979, Fig. 37 no 5783, p. 202), Arcóbriga (Martín, 1992, Fig. 4.8 nº 54), Palencia y Segóbriga (Saelices, Cuenca) (Abascal, 1986, no 288-289 y 527).

De la segunda variedad, rombos de gran tamaño, encontramos paralelos en época alto-imperial en Tiermes (Argente et alii, 1984, Fig. 110, no 80-1227, 80-788), en El Quintanar (Soria) (García Merino, 1963, ํo 32), Ercavica (Cavañaruelas, Cuenca) (Abascal, 1986, 516), Segobriga (Saelices, Cuenca) (Abascal, 1986, Fig. 81, o 414), Numancia de la Sagra (Toledo) (Abascal, 1986, no 518), Villaverde (Madrid) (Abascal, 1986, Fig. 93, $n^{\circ}$ 519). El motivo perdura hasta época bajo-imperial, como podemos ver en Clunia (Abascal, 1986, № 741). 
A.7.- Círculos en sucesión tangente o arquillos. Es un motivo frecuente en Clunia (Abascal, 1986, Fig. 53 no 244, Fig. 54, no 246) y Arcóbriga (Martín, 1992, Fig. 4.24, n² 126).

A.8.- Semicírculos en sucesión secante, adosados a una línea horizontal, los encontramos en Uxama (Burgo de Osma, Soria) (Abascal, 1986, Fig. 64, no 307), Arcóbriga (Martín, 1992, Fig. 4.24, n 129; Fig. 4.30 $\mathrm{n}^{\circ}$ 144; Fig. 4.29 no 146). Este motivo aparece asociado frecuentemente al motivo A.10 en la misma vasija.

A.9.- Líneas onduladas entrecruzadas.

A.10.- Trazos ondulados dobles, formando eses, inscritas alternativamente una en otra. Nunca aparecen aislados sino formando parte de composiciones más complicadas y constituyendo un friso horizontal, en ocasiones enmarcado por dos líneas horizontales paralelas. Encontramos paralelos en Sasamón (Abásolo-García, 1993, Fig. 35.11), Tiermes (Termancia, Soria) (Argente et alii, 1984, p. 252, fig. 101.k), Arcóbriga (Martín, 1992, Fi.g 4.8, no 54; Fig. 4.14, no 83; Fig. 4.17, no 92), así como en Caesaraugusta (calle Gavín, Zaragoza) (Beltrán Lloris, 1982, Fig. 8.3) y Complutum (Alcalá de Henares)(Abascal, 1986, Fig. 50, no 233; Fig. 63, no 302), encontrándose el motivo mucho más simplificado en estos dos últimos casos.

A.11. - Líneas dentadas o raspa de pescado, motivo que encontramos en Tiermes (Termancia, Soria) (Argente et alii, 1984, Fig. 101, N. pág. 225).

A.12.- Líneas de puntos más o menos circulares, no aparecen aislados sino que suelen formar parte de otras decoraciones más elaboradas. Encontramos paralelos de este motivo decorativo en la Calle de la Rúa (Castro Urdiales, Cantabria) (Bohigas, 1991, Fig. Il, no 5, p. 433), Arcóbriga (Martín, 1991, Fig. 4.4., no 35-36, p. 184).

A.13.- Decoración en metopas, consiste en un friso ornamental separado por grupos de líneas verticales, dentro del cual se dibujan motivos florales, zoomorfos, o dos líneas diagonales -aspas-. Este tipo de decoración parece relacionarse con las metopas propias de la terra sigillata (Abascal, 1986, p. 41). Aparece sobre todo en las cerámicas «tipo Clunia». Encontramos paralelos en Tiermes (Argente et alii, 1984, Figs. 112-113, pp. 247 y 249), Clunia (Abascal, 1986, no 213-216, 221, 239, 250 a 253), Arcóbriga (Martín, 1992, fig. 4.22.) y Calle de la Rúa (Castro Urdiales, Cantabria) (Bohigas, 1991, Fig. I, no 4, p. 432)

A.14.- Aspas: son figuras o signos en forma de $X$ que, a veces, se presentan enmarcadas por trazos horizontales. Es un motivo característico 
de las cerámicas «tipo Clunia». Este motivo que se encuentra ampliamente extendido lo encontramos en: calle de la Rúa (Castro Urdiales, Cantabria) (Bohigas, 1991, Fig. I, 3, p. 432; Fig. II, 2, 3, p. 433), Libia (Herramélluri, La Rioja) (Marcos Pous, 1979, Fig. 38, 3017, p. 203), Clunia (Coruña del Conde, Burgos) (Abascal, 1986, Fig. 35, no 168 a 174, 176; Fig. 36, no 179), Sasamón (Burgos) (Abasolo-García, 1993, Fig. 25.3), Palencia (Abascal, 1986, Fig. 36, $n^{\circ}$ 178), Tiermes (Termancia, Soria) (Argente et alii, 1984, Fig. 72, 427, p. 126) y Arcóbriga (Monreal de Ariza) (Martín, 1992, Fig. 4.1. no 7; Fig. 4.3 n 29, 32; Fig. 4.5 n 41-42).

A.15.- Líneas de bastoncillos, normalmente oblícuas, paralelos entre sí, que se sitúan cerca del borde. Dicho motivo aparece también en Tiermes (Argente et alii, 1984, Fig. $101 \mathrm{H}$, p. 225).

A.16.- Líneas onduladas paralelas en bucles (también denominados meandros, costillares o aguas), motivo decorativo de extensión más reducida, constatado en el valle medio del Ebro: Azaila -tanto en el Periodo III (300-200 a.C.) como el Periodo IV (200-50 a.C.) -, correspondiendo al tema 42 y 43 de M. Beltrán (Beltrán Lloris, 1976); Contrebia Belaisca (Botorrita, Zaragoza) (Beltrán Martínez, A., 1982, Fig. 14, p. 338) y el Poblado de San Esteban (Poyo del Cid, Teruel) (Burillo, 1981, Fig. 14.3, p. 208). Corresponde al tema 8 de Nordström, quien señala que en el s. I antes de la era se hallan flotantes, especialmente en kalathos de estilo Fonscaldes, como es el caso del que aparece en el Poyo del Cid, que se fecha ya en época imperial (Burillo, 1980, 238).

A.17.- Líneas en escalera, elípticas, motivo decorativo registrado en Tiermes (Argente et alii, 1984, Fig. 101, U, p. 225) en vasijas grandes.

A.18.- Líneas en escalera verticales, conteniendo un punto en el interior. En realidad, podemos considerarla una variante del motivo anterior.

A.19- Triángulos isósceles adosados a una línea oblícua.

A.20.- Ochos o líneas onduladas entrecruzadas a modo de gusaniIlo, formando una banda decorativa, bién horizontal, vertical, o inclinada, y no apareciendo nunca como motivo aislado sino acompañando a otras ornamentaciones. Se asocian siempre a cuellos de botellas o jarras en yacimientos como Arcóbriga (Martín, 1992, Fig. 4.15, no 89; Fig. 4.21, no 118) o Tiermes (Argente et alii, 1984, fig. 110, no 80-730), mientras que en Bílbilis únicamente aparece sobre vasos carenados que imitan la forma XLVIII de Mayet de la cerámica de «paredes finas».

A.21.- Bipennes o triángulos afrontados por el vértice, a modo de clepsidras, motivo típico de la cerámica de Azaila (Beltrán Lloris, 1976) y constatado también en Numancia (Wattenberg, 1963, Lám. XVIII 10-1308), 
Roa de Duero (Sacristán-Pérez, 1988, Fig. 7 no 1) y Sasamón (AbásoloGarcía, 1993, Fig. 34 n 10), aunque aquí los triángulos se encuentran separados por una linea horizontal. Dicha ornamentación se asocia a la cerámica tipo Clunia, formando parte de decoraciones metopadas.

A.22.- Dientes de lobo. Dicho motivo, que corresponde al tema 35 de M. Beltrán (Beltrán Lloris, 1976, Fig. 70), aparece enmarcando decoraciones más complicadas.

\section{B) Motivos vegetales}

B.1.- Palmeras, motivo muy frecuente en Contrebia Belaisca (Botorrita, Zaragoza) (Beltrán Martínez, A., 1982, Fig. 14, p. 338), constatado también en niveles antiguos de Caesaraugusta (Zaragoza), concretamente en el Palacio de los Pardo, fechado en torno a los años 15/12 a.C. (Beltrán Lloris, 1982, Fig. 8.2).

B.2.- Hojas de parra: se asocia al motivo decorativo B.6., por lo que no entraremos aquí en su descripción, puesto que se hará en dicho punto.

B.3.- Hojas en forma de punta de flecha, asociadas con zarcillos enrollados en espiral, y hojas de helecho. Motivo del que encontramos paralelos en Roa de Duero (Burgos) (Sacristán de Lama y Pérez Rodríguez, 1988, Fig. 7, p. 95).

B.4.- Bifoliáceas.

B.5.- Rosetas o aspas de brazos abultados, de la que hemos constatado dos variedades, es un motivo exclusivo de la cerámica «tipo Clunia", que aparece siempre en composiciones metopadas. Encontramos paralelos en Clunia (Abascal, 1986, no 127), Tiermes (Argente et alii, 1980, 281), Arcóbriga (Martín, 1992, Fig. 4.21 nํ 120; Fig. 4.22 nำ122).

B.6.- Ramiformes: consiste en un tallo central del que parten una serie de ramitas, motivo que aparece ya en la cerámica de Azaila (Beltrán Lloris, 1976, Fig. 74) y posteriormente lo encontramos en Arcóbriga (Martín, 1992, Fig. 4.35 no 232, p. 215).

B.7.- Guirnalda de brazos rematados en roleos: se trata de tallos serpentiformes que recorren toda la anchura del vaso y que normalmente van rematados por roleos $u$ hojas de parra. Su aparición no es muy frecuente, constatándola en escasos ejemplares y siendo característica de la forma Abascal 1986, ํo 1. Los paralelos de esta decoración se limitan a: Arcóbriga (Martín, 1992, Fig. 4.30, no 146) y Celsa (Velilla de Ebro) (Beltrán Lloris, 1979, Fig. 6, p. 203; Abascal, 1986, Fig. 7, no 1). 


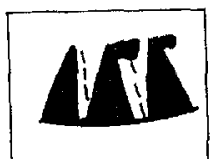

19
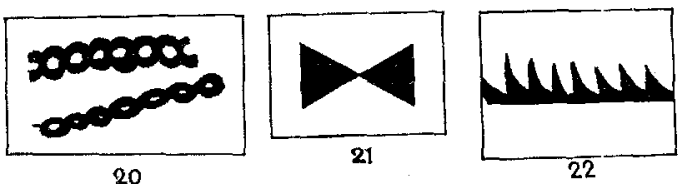

B
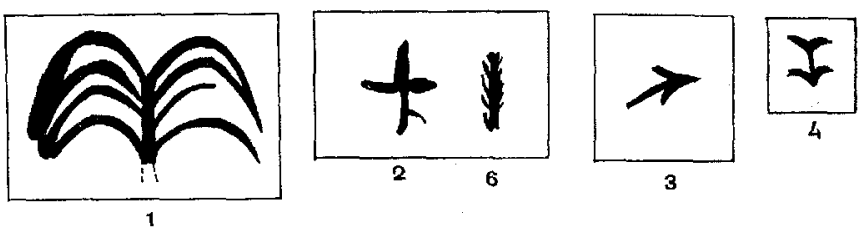

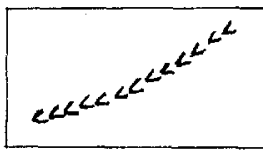

4

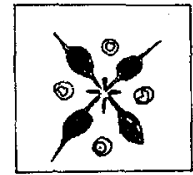

$5 a$

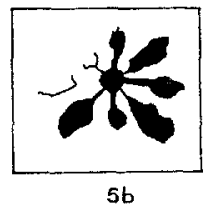

C
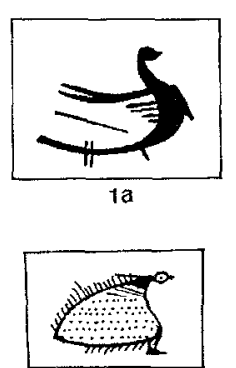

Ic

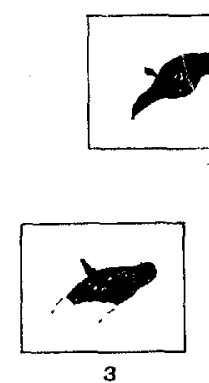

3
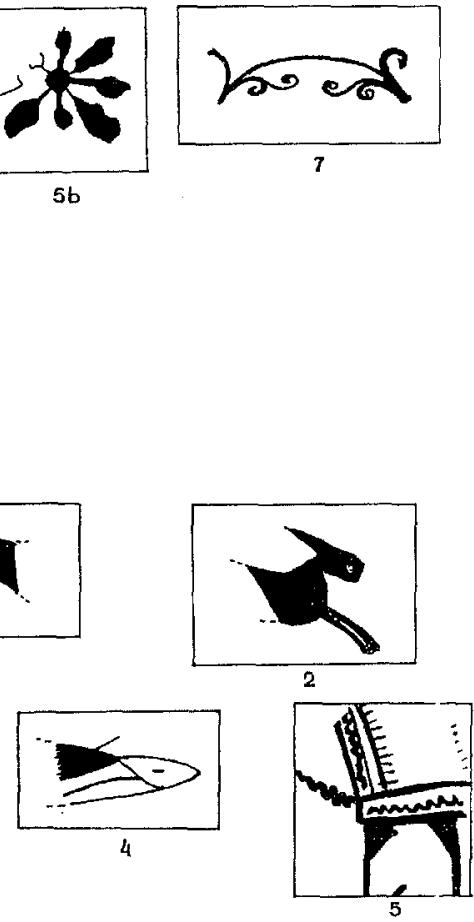


\section{C) Motivos zoomorfos}

Su aparición es infrecuente, constituyendo casos aislados y excepcionales.

C.1.- Ornitomorfos: constatados en escasos ejemplares. En un caso se trata de aves acuáticas (1a) que podrían identificarse con cisnes, en posición estática. En el otro nos encontramos ante un ave terrestre (1b).

Un interés especial merece el ejemplar (1c) de la Fig. 25 (no 93), nos encontramos ante un ave de tamaño grande, con el cuerpo moteado -relleno de líneas horizontales de puntos-, plumaje exterior sugerido por una serie de trazos oblícuos paralelos, y carente de cuello. Los paralelos más exactos de nuestro ejemplar los encontramos en Uxama (Osma, Soria) (García Merino, 1992, Fig. II, 1).

C.2.3.- Ciervos ? y lobos ? (o perro lobo ?): aparecen formando parte de composiciones metopadas, y se suelen asociar a la cerámica «tipo Clunia» o imitaciones.

C.4.- Pisciforme: es un motivo típico tanto de yacimientos ibéricos como celtibéricos, lo registramos en un solo ejemplar; no aparece aislado, sino formando parte de ornamentaciones más complicadas. Encontramos paralelos en Numancia (Wattenberg, 1963, Lám. XIII, no 2-1268, 6-1272, 5-1271, 41270), Clunia (Abascal, 1986, Fig. 56, no 266), Roa de Duero (Burgos) (Sacristán de Lama y Pérez Rodríguez, 1988, Fig. 12, p. 100), Uxama (Osma, Suria) (García Merino, 1992, Fig. II, 9), poblado de San Esteban (Poyo del Cid, Teruel) (Burillo, 1980, Fig. 51.5), aunque lleva un punteado en el interior del cuerpo; Azaila, correspondiendo al tema 164 de M. Beltrán (Beltrán Lloris, 1976, 283) y Santa Pola (Alicante) (Abascal, 1986, Fig. 107, oㅜ 607).

C.5.- Equido: Otro de los motivos, constatado en un solo ejemplar, parece tratarse de un prótomo de caballo muy esquemático, que guarda cierta similitud con los ejemplares de Numancia (Wattenberg, 1963, Lám. I, 22-1192).

\section{Morfología}

En la elaboración de la tipología hemos seguido básicamente los trabajos de Abascal (Abascal 1986) y Martín López (Martín 1992) referido a las cerámicas pintadas de Arcóbriga.

\section{Cerámica «Tipo Clunia»}

Este tipo de cerámica, definida ya por B. Taracena (Taracena, 1931-32, 90-91), y estudiada más recientemente por J.M. Abascal (Abascal, 1986) 
(taller de Los Pedregales -aunque no debemos olvidar que Tiermes tuvo también alfares locales-), presenta unas peculiares características, tanto morfológicas como técnicas. Las pastas presentan un color blanco-amarillenta (el que mejor define a estas producciones). Las paredes son muy finas, oscilando entre 2 y $4 \mathrm{~mm}$. de espesor. Las formas constatadas en nuestro yacimiento son abiertas (cuencos y vasos).

La decoración, realizada a base de pintura marrón, se desarrolla en metopas horizontales, y normalmente se sitúa en la parte superior de la vasija, no afectando a la inferior. Las metopas están separadas por haces de líneas verticales y los motivos son vegetales, geométricos 0 , más raramente, animales.

* Forma Abascal $3 \mathrm{~A}$

(Fig. 1.1-2. Fig. 2.3. Fig. 2.4)

Se trata de un cuenco carenado, cuya pared superior es cilíndrica y la inferior en forma de tronco de cono invertido. Se caracteriza por su poca altura, en relación a la anchura.

* Forma Abascal 3 B

(Fig. 2.5. Fig. 2.6)

La forma es similar a la anterior (Abascal $3 \mathrm{~A}$ ), pero con un mayor desarrollo en altura, lo que permite una mayor amplitud para la ornamentación.

\section{IMITACIONES}

La cerámica «tipo Clunia» fue imitada en otros talleres como ponen de manifiesto las cerámicas de Tiermes o Arcóbriga, además disponemos de una serie de fragmentos que constituyen ejemplos de claras imitaciones.

\section{* Formas abiertas}

El fragmento de la Fig. $2 n^{\circ} 5$ constituye una imitación de los productos clunienses y nos inclinamos a pensar que sería manufacturado si no en Bílbilis en algún taller cercano a Bílbilis. En él se ha copiado no sólo el perfil (Forma Abascal 3B) sino la decoración, se ha intentado copiar un aspa de brazos abultados cluniense y el resultado ha sido una roseta de ocho pétalos, de factura algo tosca. Otra peculiaridad es la ausencia de las líneas horizontales que delimitan el friso decorativo en los productos de 
Clunia, y finalmente el color de la pintura es negro, frente al marrón de los productos auténticos.

Técnicamente, la pasta es de color rojizo, con abundante desgrasante visible en superficie, compuesto por partículas de caliza, puntitos brillantes y presencia de algunas vacuolas. La pieza se encuentra ligeramente deformada en la pared superior.

\section{* Formas cerradas}

Disponemos únicamente de una serie de fragmentos (Fig. 17.65, Fig. 25. 92-93-94-95-96-97) que nos permiten atribuirlos a las formas 5 ó 6 de Abascal (botellas tipo lekytos). Algunos de ellos es posible que pertenezcan a la misma vasija, aunque no nos ha sido factible su reconstrucción.

Se trata de producciones claramente emparentadas con los motivos clunienses, tal como sugieren la decoración metopada y los motivos ornamentales: un ave grande, con el cuerpo moteado -relleno de líneas horizontales de puntos-y plumaje exterior formado por series de trazos oblícuos paralelos. Parece tratarse de un ave de presa, de la que encontramos paralelos en la Casa de la Atalaya de Uxama (Osma, Soria) (García Merino, 1992, Fig. II, 1). También encontramos aves moteadas en Caesaraugusta (calle Gavín) y Ciudad Rodrigo (Abascal, 1986, Fig. 50. 233 y Fig. 51. 236), aunque los ejemplares citados difieren de las grandes aves clásicas del taller de los Pedregales porque carecen del cuello estilizado, típico de los últimos.

Tal como sugiere Abascal, aunque el tipo recuerda a las aves clunienses, parece que fue fabricado en un taller/es distinto/s (Abascal, 1986, $p$. $345)$, al/a los que tal vez habría que adscribir los ejemplares de Caesaraugusta, Uxama, Ciudad Rodrigo y Bílbilis. Más compleja resulta la cronología de estos ejemplares, pués mientras Abascal considera que las piezas salmantina y zaragozana fueron fabricadas con posterioridad a los años 60-70 d.C. y antes del 90 d.C. (Abascal, 1986, p. 59), el ejemplar de Uxama se fecha en época Julio-Claudia (García Merino, 1992, p. 864), cronología que parece reforzada por nuestros ejemplares, algunos de los cuales aparecen en niveles fechados en la primera mitad del s. I d.C.

Técnicamente la pasta de nuestros ejemplares es la misma en todos los fragmentos estudiados, presenta un color marrón tostado (Cailleux $\mathrm{N}$ 53), salvo en el ejemplar no 96 de la Fig. 25 cuya superficie interior es de color rojizo (Cailleux N-57), encontrándose bastante depurada, no se aprecia desgrasante a simple vista, a excepción de puntitos brillantes de mica y algunas partículas calizas. 


\section{CERÁMICAS NO CLUNIENSES}

\section{Cuencos}

Dadas sus dimensiones serían utilizados como servicio de mesa. Mientras algunos se relacionan con formas de la cerámica común, otros presentan ciertas similitudes con el mundo de las "paredes finas" dada la extrema delgadez de sus paredes.

* Forma Arcóbriga 4

(Fig. 4.11, Fig. 4.12, Fig. 4.13, Fig. 4.14)

Morfológicamente se trata de un cuenco hemiesférico, con el borde invasado (labio engrosado hacia el interior). La decoración es muy sencilla y se limita a bandas horizontales paralelas al exterior, al interior o en las dos caras a la vez. Encontramos paralelos en el Poyo del Cid (Burillo, 1981, Fig. 37.9), Ercavica (Osuna, 1976, Fig. 21.1., p. 54), Valeria (Osuna et alii, 1977, Fig. A-1).

Abascal clasifica estos ejemplares entre las últimas producciones indigenas coetáneas a las primeras formas romanas (Abascal, 1986, p. 29, figs. 8-9), denominándolos platos.

\section{* Forma Arcóbriga 10}

(Fig. 3.7, Fig. 3.8, Fig. 3.9, Fig. 3.10)

Se trata de un cuenco con carena poco marcada, cuya pared - bitroncocónica - termina en un borde exvasado. La decoración de estos ejemplares es muy sencilla y consiste en líneas onduladas horizontales, que se situan en la parte superior de la carena.

\section{* Forma Arcóbriga 11}

Fig. 24.89)

Forma muy similar a la anterior, de la que únicamente difiere por tener la carena más marcada que la forma precedente. La decoración se caracteriza por su sencillez: líneas onduladas horizontales encima de la carena.

* Forma Bílbilis 85 ST 23-25 R-S b 54

(Fig. 5.17)

Se trata de un cuenco de tamaño grande, con el borde reentrante y carena acusada, próxima al borde, con labio redondeado y ligeramente 
engrosado. Reposaría sobre pie anular. Esta misma forma, carente de decoración, la encontramos abundantemente representada en Bílbilis dentro de la cerámica común romana (Vegas, tipo 20). Los precedentes de esta forma se encontrarían en las páteras y cuencos de borde reentrante, de técnica ibérica (Burillo, 1980, 209, Fig. 69).

* Forma Bílbilis SP I - $1 H^{\prime}-4$

(Fig. 5.16)

Cuenco o copa de tamaño pequeño, carenado, con el borde de dirección vertical y ligeramente engrosado, y cuerpo hemiesférico. La decoración, a base de líneas paralelas horizontales o bandas, se sitúa en la superficie exterior, bajo la carena.

* Forma Bílbilis BCIII - SUP.1

(Fig. 5.15)

Cuenco o plato muy similar a la forma Arcóbriga 4, de la que difiere por tener el borde más afilado y ligeramente apuntado. La decoración, a base de líneas horizontales paralelas, se sitúa en la supeficie interior, próxima al borde.

\section{COPAS DE PIE ALTO}

* Forma Arcóbriga № 54-55/ Abascal Forma 15?

(Fig. 6.18, Fig. 6.19, Fig. 6.20, Fig. 6.21, Fig. 7.22, Fig. 7.23, Fig. 7.24, Fig. 7.25, Fig. 8.26, Fig. 8.27, Fig. 8.28, Fig. 9.29, Fig. 9.30, Fig. 9.31)

Morfológicamente, se trata de recipientes de alto pie y cuerpo poco profundo, hemiesférico, con borde vuelto hacia afuera, en unos ejemplares, y con incisión o estría muy profunda, en forma de $V$, en otros. El vástago, de sección cilíndrica, constituye la zona de prensión del vaso, y su parte inferior se abre ampliamente para conseguir la estabilidad necesaria.

Son vasijas de tamaño medio y proporciones bajas. El diámetro de la boca oscila entre 12 y $15 \mathrm{cms}$. y la altura del recipiente sustentado es aproximadamente de $13 \mathrm{cms}$., el diámetro de la base es de unos $12,5 \mathrm{cms}$.

Técnicamente, la cocción en todos los ejemplares estudiados se ha realizado en atmósfera oxidante. En cuanto al proceso de fabricación, se realizaban los pies macizos por separado del cuerpo y la base, que se unían con barbotina en el proceso final. 
Su utilidad no está muy clara. Estas vasijas recuerdan, morfológicamente, a los incensarios recogidos por Vegas en su tipo 64 (Vegas, 1973, p. 154, Fig. 58), quien les otorga un uso sacro. Sin embargo, Cabré denominó a estos vasos «soporte» al estudiar las cerámicas de Azaila (Cabré, 1944), forma que deriva de la no 4 de la campaniense $B$.

Desde el punto de vista cronológico, el tipo aparece en la civilización celtibérica tardía que entra en contacto con la romanización, ej. Numancia (Wattenberg, 1963, Fig. XXX) y se prolonga hasta el s. I d.C., fabricándose tanto en cerámica común como en terra sigillata. Dentro de la cerámica pintada, Abascal encuadra estas formas entre "las últimas producciones indigenas, coetáneas a las primeras formas romanas" (Abascal, 1986, p. 29, Figs. 9-10). Según este autor, "se trata de un tipo antiguo que deja de fabricarse a finales del reinado de Nerón aproximadamente».

Encontramos paralelos de esta forma en: Tiermes (Argente et alii, 1984, Fig. 70, ํㅡ 18, p. 122), Contrebia Belaisca (Botorrita, Zaragoza) (Beltrán Martínez, 1982, Fig. 20, p. 346), Azaila (Beltrán Lloris, 1976, pp. 239 y ss, Fig. 63), Arcobriga (Martín, 1992, ํo 54-55, Fig. 4.8.) y Sasamón (Burgos)(Abasolo-García, 1993, Fig. 55).

La decoración más usual es a base de líneas horizontales paralelas, que podemos encontrar tanto en el interior como exterior del cuerpo, el pie y la base.

\section{VASOS CARENADOS}

* Forma Arcóbriga 1/ Abascal 1986, no 1, fig. 1

(Fig. 10.33, Fig. 10.34, Fig. 10.35)

Morfológicamente se trata de un vaso bitroncocónico, con borde exvasado recto, y entalle para asiento de la tapadera, que presenta una serie de acanaladuras o molduras en el cuello y carena. La mayoría de ellos presentan en su superficie exterior un ligero engobe, a excepción del vaso nํㅜ 33 Fig. 10)

La decoración se sitúa encima de la carena, enmarcada por acanaladuras y consiste en motivos sencillos: líneas onduladas horizontales y círculos concéntricos, en pintura monócroma de color pardo-grisáceo.

Atención especial merece el ejemplar no 33 (Fig. 10) que presenta decoradas tanto la zona superior como la inferior. La primera presenta una decoración vegetal consistente en una guirnalda rematada por roleos, con trazos paralelos apoyados en ellos; y la segunda una sucesión 
de semicírculos concéntricos terminados en su extremidad derecha en líneas onduladas verticales (serpentiformes). Dicho vaso presenta similitudes tanto morfológicas como técnicas con uno procedente de la colonia Lepida Celsa (Velilla de Ebro, Zaragoza), fechable hacia el cambio de Era o primeros años del s. I d.C. (Abascal, 1986, p. 58).

Por tanto, vemos que la difusión de este forma se reduce, por ahora, a Celsa (Velilla de Ebro, Zaragoza) (Beltrán Lloris, 1985, p. 104, fig. 53), Arcóbriga (Monreal de Ariza, Zaragoza) (Martín, 1992, p. 155, fig. 9, no 59-65), poblado de San Esteban (El Poyo del Cid, Teruel) (Burillo, 1980, Fig. 51,5 ) y Bílbilis (Calatayud, Zaragoza).

* Forma Arcóbriga 5

(Fig. 11.36)

Unicamente contamos con un ejemplar de esta forma, tratándose de un vaso de tamaño grande con borde exvasado y carena pronunciada, presenta una decoración vegetal muy peculiar. Desde el punto de vista cronológico se encuadraría en el s. I de la Era (Martín, 1992, p. 156).

* Forma Abascal 4?/Arcóbriga 147-148

(Fig. 11.37)

Vaso bitroncocónico con dos asas, que Abascal denomina «vasos de borde exvasado con cuerpo globular y pared recta». El cuerpo inferior es curvo, globular, con una suave inflexión arranca la pared recta, que termina en un borde o bien exvasado o en forma de bastoncillo.

Este ejemplar presenta una decoración muy peculiar, consistente en haces de líneas onduladas paralelas - bucles o meandros-, que se sitúan en la parte superior del cuerpo, decoración que difiere de los ejemplares clunienses, que únicamente presentan grandes aspas, a lo que hay que añadir la presencia de asas en nuestro ejemplar.

Esta misma forma así como su decoración la encontramos en Contrebia Belaisca (Botorrita, Zaragoza), donde aparece incluida dentro de la cerámica ibérica (Beltrán Martínez, 1982, Fig. 19, 18, p. 345). Esta forma parece tratarse o derivar de las cráteras de pie atrofiado. También la encontramos en Arcóbriga, aunque con decoración de aspas (Martín, 1992, № 147-148, Fig. 31). Es una forma frecuente en el valle del Ebro, mientras Pellicer la sitúa entre el 200 y el 50 a.C., para M. Beltrán pertenece a fines del s. II y primera mitad del I a.C. (Burillo, 1980, 215). 


\section{* Forma Abascal 9}

(Fig. 12.38, 12.39, 12.40, 12.41)

Vasos con la pared superior cilíndrica y borde exvasado en unos ejemplares ( $n^{-} 38,39$ y 41) o en forma de bastoncillo en otros ( $\left.n^{\circ} 40\right)$. Desconocemos la parte inferior del cuerpo, pero parece ser que uniría a la superior por medio de una suave carena.

La decoración, situada en la parte superior del cuerpo, presenta dos modalidades: grandes aspas, inscritas en casetones dentro de un friso horizontal metopado por líneas verticales paralelas, cuya cronología se situa en la segunda mitad del s. I d.C. (Abascal, 1986, p. 73); o trazos oblícuos paralelos formando triángulos, fechable en la primera mitad del s. I d.C. (Abascal, 1986, p. 72).

Esta forma aparece abundantemente representada en Sasamón (Burgos) donde recibe el nombre de cuencos «carenoides» (AbásoloGarcía, 1994, Figs. 26-32), caracterizados por la mitad inferior del cuerpo hemiesférica y fondo plano, con pie suavemente esbozado.

* Vasos que imitan la forma Mayet XLVIII (Mayet, 1975, p. 110)

(Fig. 13.42, Fig. 13.43, Fig. 13.44, Fig. 13.45, Fig. 13.46)

Se trata de vasos de gran calidad y elaboración cuidada, que recuerdan a las cerámicas de paredes finas, atendiendo a la extrema delgadez de sus paredes. La forma es de taza carenada, con borde exvasado y cuerpo inferior globular, que reposa sobre un pie del tipo denominado de "galleta». La decoración se sitúa en la parte superior de la pared y normalmente presenta un color rojo vinoso.

Encontramos paralelos de esta forma en Numancia (Romero Carnicero, 1978, Fig. 1, pp. 396-402) y Tiermes (Argente et alii, 1982, pp. 120-121, Fig. 73).

\section{BOTELLAS/JARRAS}

Debido a la fragmentariedad del material objeto de estudio, hemos podido constatar escasas formas; sin embargo, disponemos de gran número de fragmentos correspondientes a cuerpos de botellas o jarras, que no nos permiten reconstruir la forma completa. En algunos casos podemos observar la presencia de piezas grandes de cuerpos anchos globulares o carenados y de asas en algunos ejemplares (un único fragmento corresponde a 
un asa torsa). A pesar de ello, desde el punto de vista decorativo tales fragmentos presentan sumo interés por su riqueza y variedad temática. La ornamentación en estos ejemplares se dispone habitualmente en el cuello, hombro o parte superior del recipiente.

\subsection{Botellas}

Hemos denominado botellas a las vasijas de cuello angosto, destinadas a contener líquidos y provistas normalmente de un asa.

* Forma Arcóbriga 5

(Fig. 14.50, Fig. 14.51)

Es un olpe o botella de boca estrecha, con borde recto, que presenta acanaladuras en uno de los ejemplares, y un estrangulamiento al inicio del cuello.

La decoración consiste en líneas onduladas verticales. Desde el punto de vista cronológico, esta forma parece situarse a lo largo del s. I d.C. (Martín, 1992, p. 156).

* Forma Arcóbriga 6

(Fig. 14.48, Fig. 14.54)

Botella con la boca en forma de embudo y borde recto, con entalle interior. La decoración consiste en líneas onduladas verticales.

\subsection{Jarras}

Denominamos jarras a las vasijas destinadas a contener líquidos, que formarían parte del servicio de mesa, caracterizadas por tener una boca ancha y estar provistas de asas. Dado lo fragmentario de las piezas que conservamos de Bílbilis, no podemos hacer diferenciaciones entre jarras con una o dos asas.

* Jarra con el borde moldurado

(Fig. 14.53)

Se trata de una jarrita con el borde moldurado y un cuello recto que se amplia al exterior. La conjunción borde-cuello da lugar al interior a un rebaje para asiento de la tapadera. El borde presenta al exterior dos molduras. 
Es una forma muy frecuente y abundante dentro de la cerámica común romana y engobada, no sólo en Bílbilis sino en la mayor parte de los yacimientos del valle alto y medio del Ebro.

\subsection{Garrafa}

(Fig. 14.52)

Bajo esta denominación incluimos un fragmento caracterizado por poseer una boca más ancha que en el caso de las botellas, cuello destacado y un asa, con carena en el hombro y un cuerpo ancho y cilíndrico. El estado fragmentario de nuestros ejemplares no nos permite hacer más precisiones. El borde es de perfil subtriangular o "cefálico", con marcadas reminiscencias indígenas. La decoración es muy sencilla: a base de líneas horizontales paralelas.

\section{URCEI (ORZAS)}

Se trata de recipientes cuya utilidad sería la de guardar miel, vinagre, conservas de frutas y verduras (Hilgers, p. 299).

Desde el punto de vista morfológico tienen el cuerpo ovoide y el borde invasado o exvasado, normalmente están provistas de dos asas. Son formas de tradición indígena cuyos galbos recuerdan a vasijas similares del mundo celtibérico.

* Forma Arcóbriga 1

(Fig. 18.71, Fig. 18.72, Fig. 18.73)

Se trata de una vasija globular, cuyo diámetro oscila entre 23 y 30 cms., con borde reentrante, cuerpo globular y pequeñas asas geminadas.

La decoración de estos ejemplares es a base de círculos concéntricos y grupos de líneas onduladas en unos ejemplares, o líneas horizontales paralelas en otros.

El borde presenta una decoración a base de líneas paralelas en su parte superior.

* Forma Arcóbriga 2

(Fig. 19.74, Fig. 19.75)

Es una vasija de cuerpo ovoide, con borde vuelto hacia afuera. La decoración suele ser más simple que en la forma anterior: a base de líneas horizontales paralelas. 
* Forma Arcóbriga 3

(Fig. 19.76, 20.77, 20.78)

Corresponde a una vasija con el cuello nétamente diferenciado del cuerpo, que sería ovoide, por una carena. El borde vuelve hacia afuera y en algunos casos presenta un perfil en forma de «pico de pato» o «cuello de cisne». La decoración se sitúa en todos los ejemplares encima de la carena. Son formas de clara tradición indígena.

* Forma Wattenberg 1963, 349

(Fig. 21.79)

Son vasijas de amplio cuerpo, piriforme o globular, con borde recto de dirección vertical y hombro marcado por una carena pronunciada. El cuerpo lo conocemos por ejemplares paralelos, mientras en Numancia (Wattenberg, 1963, 349) es piriforme, en La Clínica (Calagurris Ivlia, Calahorra - La Rioja-) es globular. También las encontramos en el campamento romano de Cáceres el Viejo (Ulbert, 1984, Lám. 46, 548). Podemos considerar la forma como una perduración indígena.

La decoración de estos ejemplares se reduce a semicírculos concéntricos.

* Forma Tiermes tipo $1 \mathrm{~b}$

(Fig. 21.80, 21.81)

Es una vasija que sigue la tradición de las tinajas de borde zoomorfo, también conocidas como cefálicas o de cuello de cisne. Su cronología se sitúa del 179 al 29 a.C. en Numancia y en la zona del Ebro Medio (Burillo, 1980, pp. 225-228).

* Forma lnédita

(Fig. 25.98)

Corresponde a una vasija de borde vertical, liso, ligeramente exvasado, y cuerpo globular u ovoide, con varias acanaladuras marcando el paso del cuello al cuerpo. Presenta ciertas analogías con la forma Mayet XVIII de la cerámica de paredes finas. El acabado es muy cuidado y la decoración es muy sencilla a base de líneas onduladas verticales.

6. VASIJAS TIPO KALATHOS

(Fig. 22.82, Fig. 22.83, Fig. 22.84, Fig. 23.85, Fig. 23.86)

Morfológicamente, este recipiente - cuya forma recuerda a un sombrero 
de copa invertido - es bastante profundo, con cuerpo troncocónico, y borde desarrollado hacia afuera, alargado y recto, con fondo horizontal.

Esta forma es característica del área ibérica y presenta una gran difusión en los siglos II y I a.C., pero también la encontramos en yacimientos celtibéricos como Belmonte, Alto Chacón y el Poyo del Cid (Burillo, 1981, p. 262). La decoración se sitúa en la superfície exterior y parte superior del borde. En la primera consiste bien en líneas horizontales o en semicírculos concéntricos y en la segunda en líneas paralelas al borde, perpendiculares o triángulos combinados con ochos.

La decoración de semicírculos concéntricos aparece especialmente en kalathos del estilo Fonscaldes, propios de época republicana (Colominas, 1923, pp. 602-604).

\section{IMITACIÓN DE LA FORMA MAYET III}

(Fig. 24.88)

Morfológicamente se trata de vasitos de forma ovoide, con borde ganchudo que imitarían a los cubiletes de procedencia italiana, conocidos como la forma Mayet III (Mayet, 1975, p. 29). Cronológicamente, dentro de la cerámica de paredes finas, el prototipo italiano está presente en territorio aragonés desde el primer tercio del s. I a.C., siendo muy abundante en contextos augústeos e, incluso, apareciendo en el estrato de fines de Augusto o comienzos de Tiberio del solar angular a las calles Latorre/ Manuela Sancho de Caesaraugusta (Zaragoza) (Mínguez, 1991-92, 461).

La decoración, a base de líneas horizontales paralelas o bandas, se sitúa en la superficie exterior.

\section{CERÁmICA BAJO-IMPERIAL}

- CANTIMPLORAS

Forma Abascal 26?

(Fig. 24.87)

La forma corresponde a un recipiente lenticular con cuello y boca muy estrechos, dotado de asas. Es la forma que en los repertorios de terra sigillata suele denominarse Hermet 13 y su uso debió ser el de cantimplora.

Tanto por el tipo de pasta, como por la decoración, podemos considerarla una producción bajo-imperial, Abascal fecha ejemplares similares, 
procedentes de Segóbriga (Saelices, Cuenca) en el s. IV d.C. (Abascal, 1986, 206).

\section{- JARRAS}

* Formas Indeterminadas

(Fig. 24. 90, 91)

Agrupamos en este apartado unos fragmentos de jarras que, por desgracia, no pueden adscribirse a una forma concreta. Corresponden al cuello-inicio del cuerpo y cuerpo globular respectivamente de sendas jarras. Sus características técnicas (acabado poco cuidado, líneas del torno sin alisar, así como el tipo de pasta empleada) y decorativas nos inducen a pensar que se trata de productos tardíos. A lo que hay que añadir su aparición en niveles de abandono del yacimiento. Muy interesante resulta la decoración de la Fig. 24.91, consistente en metopas enmarcadas por doble linea horizontal, en las que se suceden puntas de flecha y lazos y que parece inspirarse en los sistemas decorativos de la terra sigillata hispánica.

\section{CONCLUSIONES}

El conjunto de cerámicas pintadas estudiadas procedentes del Municipium Augusta Bilbilis es un exponente más en el ya conocido auge que tuvo la ciudad en el siglo I de la Era. Sin embargo, dentro del conjunto podemos establecer una serie de grupos diferenciados, atendiendo tanto a sus características tanto morfológicas, como técnicas o decorativas: cerámicas de tradición celtibérica, de tradición ibérica, tipo Clunia e imitaciones, cerámicas de tradición indígena propiamente dicha, imitaciones de paredes finas y finalmente cerámicas tardías.

Una característica es el predominio exclusivo de las cerámicas fechadas en época altoimperial, frente a la presencia minoritaria de cerámicas tardías, fenómeno constatado en otros conjuntos cerámicos del yacimiento como es el caso de las cerámicas comunes, todo ello índice de la temprana decadencia de la ciudad a lo largo del s. II, siendo en el s. V un lugar abandonado (Martín-Bueno, 1975, 63).

Las cerámicas pintadas de tradición celtibérica se caracterizan por su sencillez decorativa a base de líneas horizontales paralelas o círculos concéntricos, dispuestos en el cuello o panza de la vasija. Morfológicamente este grupo está representado por vasos ovoide-globulares (orzas), con bordes zoomórficos («pico de pato» o «cuello cisne»). 
Otras cerámicas nos hablan de una inclinación hacia la facies cultural ibérica, concretamente las vasijas tipo "kalathos", la crátera de pie atrofiado con asas, así como las decoraciones de meandros, bucles y palmeras. Son estos materiales los que podriamos considerar de mayor antigüedad, debido no sólo a su aparición en el sector denominado CIII (niveles e-p) donde se localizan los materiales cronológicamente más antiguos pertenecientes a este yacimiento, que podrian remontarse al primer tercio del s. I d.C.--, sino también debido a su presencia en yacimientos como Contrebia Belaisca (Botorrita, Zaragoza), ciudad que presenta niveles de destrucción fechados en época sertoriana (Beltrán Martínez, 1982).

La cerámica «tipo Clunia» está escasamente representada, pues disponemos de unos cuantos fragmentos, algunos pertenecientes presumiblemente al mismo vaso. Pero resultan sumamente interesantes las imitaciónes estudiadas, que suponemos productos de un taller local/regional.

El estudio de la cerámica pintada nos plantea una serie de interrogantes, sin respuesta por el momento: el/los centro/s de producción que abastecían a la ciudad, ubicación y características, etc. Así como en lo referente a las cerámicas pintadas engobadas*, tenemos la certeza de su procedencia del alfar de Turiaso (Tarazona) -en base a características técnicas y morfológicas-, carecemos de datos suficientes y fidedignos en lo relativo a la cerámicas pintadas sin engobe, ya que por el momento los únicos análisis de pastas efectuados son los del taller de Los Pedregales (Clunia, Burgos), y de otros centros locales de producción como Tiermes o Arcóbriga no se han realizado estudios fisico-químicos de pastas que puedan servir como patrones comparativos.

A éste problema, que afecta al valle medio del Ebro, vienen a añadirse otra serie de interrogantes relativos al valle alto del Ebro: la presencia en Varea (Logroño, La Rioja) de un fragmento de vaso de paredes finas de forma Unzu 3/Aguarod I con decoración de hojas de agua pintadas, lo que apunta un dato más relativo a la decoración de estos vasos: no sólo con barbotina blanca sino también con pintura, y abre un abanico amplio de talleres aún desconocidos fabricando estas manufacturas.

\section{BIBLIOGRAFIA}

ABÁsolo J.A.; CoRtÉs, J.; PÉREZ, F.; VIGHI, A., 1984: Excavaciones en el yacimiento de La Morterona, Saldaña (Palencia), Diputación Provincial de Palencia.

* Estas cerámicas, que no se incluyen en este trabajo por considerar que merecen un tratamiento diferenciado, serán publicadas en breve. 
ABÁsolo, J.A. y Garcia, R., 1993: Excavaciones en Sasamón (Burgos), E.A.E. 164.

Abascal Palazón, J.M., 1984: "La cerámica pintada romana del Museo Municipal de Madrid", Estudios de Prehistoria y Arqueologia Madrileñas 3, pp. 75-157.

Abascal Palazón, J.M., 1986: La cerámica pintada romana de tradición indígena en la Península Ibérica. Centros de Producción, comercio y tipología. Departamento de Historia Antigüa de la Universidad de Alicante. Madrid.

AmARÉ, M‥T., 1984: «Avance al estudio de un posible alfar romano en Tarazona: III. La cerámica engobada decorada", Turiaso V, pp. 107-139.

AmARÉ, $M^{\mathrm{a}}$.T. y AGUAROD, $M^{\mathrm{a}}$.C., 1987: «Pervivencia de tradiciones cerámicas celtibéricas en época imperial romana», I S.C. Daroca (Zaragoza) 1986, pp. 97-104.

Argente, J.L.; Argente, I.; de la Casa, C.; Díaz, A.; Fernández, V.; Gonzálezz, A.; Teres, E., 1984: "Tiermes /l. Campañas de 1979 y 1980", E.A.E. 128, Madrid.

Argente, J.L.; de la Casa, C.; Díaz, A.; Izouierdo, J.M.; Jimeno, A.; Revilla, M.L., 1980: Tiermes I, E.A.E., 111, Madrid.

BELTRÁN LlóRIS, M., 1976: Arqueología e Historia de las ciudades antiguas del Cabezo de Alcalá de Azaila (Teruel), Monografías Arqueológicas, XIX, Zaragoza.

BeltRÁN LloRIS, M., 1979: «La colonia Victrix lulia Lepida Celsa, Velilla de Ebro (Zaragoza), primeros resultados de las excavaciones", R.S.L., XLV, pp. 183-204.

Beltrán Lloris, M., 1982: La Arqueología de Zaragoza: Ultimas investigaciones, Museo de Zaragoza.

Beltrán Lloris, M.; Sánchez Nuviala, J.J.; Aguarod Otal, Mª.C.; Mostalac Carrillo, A., 1980: Caesaraugusta I (campañas 1975-1976), E.A.E., no 108, Madrid.

Beltrán MARTínez, A., 1982: "Excavaciones arqueológicas en Contrebia Belaisca (Botorrita, Zaragoza)", N.A.H. 14, Madrid, pp. 319-364.

BOHIGAS ROLDÁN, R., 1991: "Cerámicas pintadas romanas en Castro Urdiales (Cantabria): solar no 15 de la calle de la Rua», XX C.N.A., Zaragoza, 1991, pp. 427 y ss.

BuRillo MozotA, F., 1980: El valle medio del Ebro en época ibérica. Contribución a su estudio en los ríos Huerva y Jiloca Medio, Institución Fernando el Católico, Zaragoza.

Burlllo Mozota, F., 1981: «Poblado de San Esteban (El Poyo del Cid, Teruel). Campaña de $1976 "$, N.A.H., 12, pp. 187 y ss.

CABRÉ, J., 1944: Corpus Vasorum Hispanorum. Azaila. Madrid.

Castiella Rodriguez, A., 1977: La Edad del Hierro en Navarra y Rioja. Pamplona.

Colomina RocA, J., 1923: "El forn ibèric de Fontscaldes", Anuari de I'Institut d'Estudis Catalans, vol. VI, MCMXV-XX, Barcelona, pp. 602-604.

DE LA CASA, C.; DOMENECH, J.M.; IzQUIERdo, J.M.; TeRES, E., 1994: Tiermes III. Excavaciones realizadas en la Ciudad Romana y en las Necrópolis Medievales (Campañas de 1981-1984), E.A.E., $n^{\circ} 166$, Madrid.

FERNÁNDEZ GALIANO, D., 1977: “Un nuevo tipo de cerámicas romanas de tradición celtibérica», Segovia y la Arqueología romana, P.E. 27, Barcelona, pp. 177-184.

Fernández Galiano, D., 1984: Complutum I. Excavaciones, E.A.E. 137, Madrid.

GARCIA Y BELLIDO, A., 1970: "Los hallazgos cerámicos del área del templo romano de Córdoba", Anejos del A.E.A., Madrid. p. 9.

GarcíA Dominguez, E., 1961: “Cerámica pintada de Lancia. Campañas 1957 y 1958", C.A.N., VI, Oviedo, 1959, Zaragoza 1961, pp. 173-176.

García Merino, M., 1967: "Tres yacimientos de época romana inéditos de la provincia de Soria", B.S.E.A.A. XXXIII, Valladolid.

García Merino, C., 1992: "Cerámica pintada con decoración plástica de Uxama», Actas del II Symposium de Arqueología Soriana, (Homenaje a D. Teógenes Ortego y Frías, 19-21 de octubre de 1989), Colección Temas Sorianos $n^{\circ} 20$, pp. 851-864.

HILGERS, W., 1969: Lateinische Gefäsnamen. Bezeichmungen Funktion und Form römischer Gefasse nach den antiken Schritquellen, B.J., Band 31, Dusseldorf.

Marcos Pous, A., 1979: Trabajos arqueológicos en la Libia de los berones (Herramélluri), Biblioteca de temas riojanos, $n^{\circ} 24$, Logroño.

MARTIN-Bueno, M., 1975: Bilbilis. Estudio histórico-arqueológico, Zaragoza.

MARTín López, A., 1992: "Cerámica pintada" en CABAlleRo ZOREDA, L., Arcóbriga II. Las cerámicas romanas, Institución Fernando el Católico, Zaragoza, pp. 151-221.

Martínez Martín, A. y HeRnández Urizar, E., 1992: "Material de época romana hallado en las excavaciones de la necrópolis celtibérica de Carratiermes (Montejo de Tiermes, Soria)", 
Actas del I/ Symposium de Arqueología Soriana, (Homenaje a D. Teógenes Ortego y Frías, 19-21 de octubre de 1989), Colección Temas Sorianos no 20, pp. 797-813.

MAYET, F., 1975: Les céramiques à parois fines dans la Peninsule Iberique, Publications du Centre Pierre Paris, 1, París.

MingueZ, J.A, 1991-1992: «La cerámica de paredes finas en la colonia Lepida/Celsa (Velilla de Ebro, Zaragoza. Su relación con el territorio aragonés», Zephyrus XLIV-XLV, pp. 457-470.

Osuna, M.; Suay, F.; Fernández, J.J.; Valiente, S.; Rodriguez, A., 1977: Valeria Romana I, Cuenca.

OsunA, M., 1976: Arqueología Conquense. Ercavica I. Aportación al estudio de la Romanización de la Meseta. Cuenca.

Romero CARNicero, Ma.V. y F., 1978: "Cerámicas imperiales con engobe rojo y decoración pintada procedentes de Numancia", BSAA, XLIV, pp. 396-403.

SACRistán de LAmA, J.D. Y Pérez Rodriguez, F., 1988: "Un interesante conjunto tardo-celtibérico", Sautuola V, (Estudios en homenaje al padre Carballo), Santander 1986-1988, pp. 81-113.

SESMA, J. y GARCíA, M.L., 1994: “Coscojal. Una villa suburbana y su taller de cerámica común y pigmentada en el valle del Aragón (Navarra)", Cuadernos de Arqueología de la Universidad de Navarra, 2, pp. 219-260. (Vid. Fig. 3 no 12 y 13, pág. 252).

TARACENA, B., 1931-32: La cerámica de Clunia. APM II-III, pp. 85-91.

UlberT, G., 1984: Cáceres el Viejo, Ein spätrepublikanisches Legionslager in SpanischExtremadura, Madrider Beiträge, Band 11.

VEGAS, M., 1973: Cerámica común romana del Mediterráneo Occidental, P.E. 22, Barcelona.

WATTENBERG, F., 1963: Las cerámicas indígenas de Numancia, B.P.H. IV, Madrid.

\section{ABREVIATURAS}

A.E.A. Archivo Español de Arqueología

B.J. Bonner Jarhbücher

B.P.H. Biblioteca Praehistorica Hispana

B.S.E.A.A. Boletín del Seminario de Estudios de Arte y Arqueologia

C.A.N. Congreso Arqueológico Nacional

E.A.E. Excavaciones Arqueológicas en España

N.A.H. Noticiario Arqueológico Hispano

P.E. Publicaciones Eventuales

R.S.L. Rivista di Studi Liguri

S.C. Simposium Celtíberos

\section{CATÁLOGO}

A continuación recopilamos todias las piezas o fragmentos analizados en este estudio. Dado que una descripción individualizada de cada de una de las piezas o fragmentos sería muy extensa, hemos optado por la confección de una serie de tablas. La metodología empleada ha sido la siguiente:

En primer lugar, y en la parte superior aparece la forma en que ha sido clasificado cada uno de los fragmentos.

Las tablas han sido divididas en los siguientes apartados:

№: Numeración que ha recibido cada una de las piezas. 
Sigla: referencia de cada una de las piezas dentro del inventario de excavación.

Sector: zona de excavación concreta o edificio dentro del cerro Bámbola (Teatro, Termas, Viviendas, etc.).

Nivel: situación de la pieza dentro de un determinado nivel o estrato de la excavación.

F. fragmento: indicamos la parte de la pieza que se conserva, para lo cual hemos utilizado las siguientes abreviaturas:

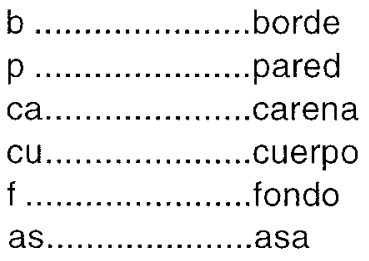

0/cm.: diámetro expresado en centímetros, indicamos el diámetro de la pieza en el borde, aunque en la mayoría de los casos el fragmento no lo proporciona, por ello el apartado permanece en blanco.

Figura: numeración que ha recibido el fragmento dentro del apartado gráfico, en el caso de los fragmentos no dibujados permanece en blanco.

Color pint. Color de la pintura: únicamente se especifica cuando el color de la misma es rojo vinoso, si aparece en blanco damos a entender que es pardo-grisácea o negra.

Dec. Decoración: se hace referencia a la clasificación de motivos decorativos dentro del apartado «decoración».

Dentro de cada una de las formas, en la confección del catálogo, exponemos a continuación el orden seguido para su elaboración.

\section{EDIFICIOS PÚBLICOS}

\section{Templo-Foro}

* ST = Sector Templo $(1971,1972,1975,1980,1981,1982,1983$, 1985)

* ST-T III (Foro) Conexión Teatro-Foro

¿Castellum Aquae?

* ST CA (1980) 
Teatro

* T I 1975, 1976.

* T II 1975, 1978.

* T III 1978, 1982, 1983.

* T IV 1975.

* T VI 1983

Termas

* BC II 1972.

* B II 1978, 1979, 1980.

Cisternas

${ }^{*} \mathrm{CH} \mathrm{AB}$

${ }^{*} \mathrm{CH}$ C 1 1972. Cisterna junto al Foro.

${ }^{*} \mathrm{CH}$ A 41978.

* $\mathrm{CH}$ A 71978.

${ }^{*} \mathrm{CH}$ A 61982.

${ }^{*} \mathrm{CH}$ B1 a y b 1982.

\section{VARIOS CORTES Y CATAS}

* SB I Santa Bárbara, Corte ladera Sur 1976.

* SB II Barranco del Teatro 1978.

* SP I Muralla Sur exterior 1971, 1972, 1975.

* BC III 1972.

* BC III M Muralla 1972.

* BC III MT Torre de Muralla 1972, 1982.

${ }^{*}$ BC IV 1972.

* C I Zona Central 1975, 1977.

* C III Zona central 1981, 1982.

* SP FE Catas Barranco de los sillares.

* SP MA

* SP MB

* SP P Colector. 


\section{VIVIENDAS}

* SP II 1972 Viviendas, Este de las Termas.

* SP III 1977, Viviendas parte baja, 1988.

* BC I 1971, 1972, Viviendas.

* C II 1978, 1979, 1982.

* SP A Casa de la Fortuna.

* SP B

* SPF "

* SP O "

$\mathrm{CS}=$ Colección Samitier .

Forma Abascal $3 \mathrm{~A}$

\begin{tabular}{|c|c|c|c|c|c|c|c|c|c|}
\hline$N^{0}$ & SIGLA & SECTOR & NIVEL & $F$ & Olcm. & FIGURA & C. PINT. & DECORACIÓN & PASTA \\
\hline 1 & BIL 83 ST $63-65$ e 675 & Templo & e & $b-p$ & 13 & $1.1-2$ & & A.12.13 B.5 Clb C2 & 1 \\
\hline 2 & BIL 85 ST 41 N'O' 209 & Templo & & $b-p$ & 14 & 2.4 & & A.13 & 1 \\
\hline 3 & BIL SPP 209 & Colector & & $b-p$ & 15 & 2.3 & & A.13.14 & $1 ?$ \\
\hline
\end{tabular}

Forma Abascal $3 B$

\begin{tabular}{|c|c|c|c|c|c|c|c|c|c|}
\hline № & SIGLA & SECTOR & NIVEL & F. & $\mathrm{O} / \mathrm{cm}$. & FIGURA & C. PINT. & DECORACIÓN & PASTA \\
\hline 4 & BIL 83 ST Q 5 C 8 & Templo & $c$ & $b-p$ & 14,8 & 2.5 & & A. $13 B .5 b$ & $4 a$ \\
\hline 5 & C.S.624 & C. Samitier & & $\mathrm{p}-\mathrm{ca}$ & & N.D. & & A.12.13 & 1 \\
\hline 6 & BIL 85 ST 7-9 R-S b 16 & Templo & $b$ & $b-p$ & 13 & N.D. & & A. 12 & 2 \\
\hline 7 & BUL $82 C \| 9 E C 13$ & Viviendas & c & $b-p$ & 14 & 2.6 & & A.2.14 & 2 \\
\hline
\end{tabular}

CUENCOS Forma Arcóbriga 4

\begin{tabular}{llcccccccc}
\hline № & \multicolumn{1}{c}{ SIGLA } & SECTOR & NIVEL & F. & O/cm. & FIGURA & C. PINT. & DECORACIÓN & PASTA \\
\hline 8 & BLL 85 ST 35-37 T-U c 113 Templo & c & b-p & 18 & 4.13 & A.1 & 2 \\
9 & BLL 83 TV DE 47/57/60 & Teatro & & b-p & 17 & 4.11 & A.1 & 2 \\
10 & BLL 79 Bll 6H 42 & Termas & & b-p & 18,2 & 4.12 & A.1 & 2 \\
11 & BIL 79 BII 10-E 53 & Termas & & b-p & 19,2 & 4.14 & A.1 & 2 \\
\hline
\end{tabular}

CUENCOS Formas indeterminadas

\begin{tabular}{llllcccccc}
\hline № & \multicolumn{1}{c}{ SIGLA } & SECTOR & NIVEL & F. & O/cm. & FIGURA & C. PINT. & DECORACIÓN & PASTA \\
\hline 12 & BIL BC III Sup. 1 & Muralla & sup. & b-p & 18 & 5.15 & A.1 & 2 \\
13 & BLL SPI 1H' 4 & Muralla & & b-p & 13,1 & 5.16 & A.1 & 2 \\
14 & BIL 85 ST 23-25 R.S b 54 & Templo & b & b-p & 26 & 5.17 & A.1 & 3 \\
\hline
\end{tabular}


CUENCOS Forma Arcóbriga 10

\begin{tabular}{lllllccccc}
\hline № & \multicolumn{1}{c}{ SIGLA } & SECTOR & NIVEL & F. & O/cm. & FIGURA & C. PINT. & DECORACIÓN & PASTA \\
\hline 15 & BIL BC II-1 C- 5 & Termas & b-p & 17 & 3.7 & A.3a & 2 \\
16 & BIL BC II-2 F- 17 & Termas & b-p & 12 & 3.10 & A.3a & 2 \\
17 & BIL BC $\|-2$ E- 15 & Termas & b-p & 13 & 3.9 & A.3a & 2 \\
18 & BIL CI 421 & Catas & b-p & & N.D. & A.3a & 2 \\
\hline
\end{tabular}

CUENCOS Forma Arcóbriga 11

\begin{tabular}{|c|c|c|c|c|c|c|c|c|c|}
\hline № & SIGLA & SECTOR & NIVEL & F. & $\mathrm{O} / \mathrm{cm}$. & FIGURA & C. PINT. & DECORACIÓN & PASTA \\
\hline 19 & BIL 83 ST $10 \mathrm{P}^{\prime} \mathrm{Q}^{\prime}$ b 13 & Templo & $b$ & $b-p$ & & N.D. & & A.3a & 2 \\
\hline 20 & BUL 85 ST 63 O'P' 15 & Templo & & $b-p$ & & 24.89 & & A.3a & 2 \\
\hline
\end{tabular}

CUENCOS Forma Arcóbriga 12

\begin{tabular}{lrllllllll}
\hline № & SIGLA & SECTOR & NIVEL & F. & O/Cm. & FIGURA & C. PINT. & DECORACIÓN & PASTA \\
\hline 21 & BIL BCII 2E 19 & Termas & & b-p & 13 & 3.8 & & A.3a & 2 \\
\hline
\end{tabular}

CUENCOS Forma Arcóbriga 13

\begin{tabular}{lllllllllc}
\hline No $^{\circ}$ & \multicolumn{1}{c}{ SIGLA } & SECTOR & NIVEL & F. & O/cm. & FIGURA & C. PINT. & DECORACIÓN & PASTA \\
\hline 22 & BIL BC $\|-1 B^{\prime} 14$ & Termas & & b-p & 15 & N.D. & & A.1.14 & 2 \\
23 & BIL $82 \quad$ CI 1,2 F $\quad 512$ & Viviendas & c & b.p & 15 & N.D. & & & 2 \\
\hline
\end{tabular}

VASOS CARENADOS Forma Arcóbriga 1/ Abascal 1986, 1

\begin{tabular}{|c|c|c|c|c|c|c|c|c|c|}
\hline № & SIGLA & SECTOR & NIVEL & $\mathrm{F}$. & $\mathrm{O} / \mathrm{cm}$ & FIGURA & C. PINT. & DECORACIÓN & PASTA \\
\hline 24 & $\begin{array}{l}\text { BIL } 83 \text { ST 3-5 R-S c } 29 l \\
5 \text { Q } 29\end{array}$ & Templo & $c$ & $b-p$ & 11,9 & N.D. & & A.3a A. 15 & 2 \\
\hline 25 & BIL 83 ST Q $5 d 27$ & Templo & $d$ & $b-p$ & 11,8 & N.D. & & A. 15 & 2 \\
\hline 26 & BIL 83 ST $11-13$ NO a 29 & Templo & a & $b-p$ & & 10.34 & & B.7 & 2 \\
\hline 27 & BIL 83 ST 15 Q b 6 & Templo & $\mathrm{c}$ & $b-p$ & 11 & N.D. & & A. 15 & 2 \\
\hline 28 & BIL 83 ST 42 J' c 2 & Templo & $c$ & $\mathrm{cu}$ & 22 & 10.33 & & A.5 B. 7 & 2 \\
\hline 29 & BIL 85 ST 4R-S c 40 & Templo & $\mathrm{c}$ & $b-p$ & 13,9 & N.D. & & & 2 \\
\hline 30 & BIL 85 ST 7.9 R-S b 17 & Templo & $b$ & $b-p$ & 12 & 10.35 & & A.3 a A.15 & 2 \\
\hline 31 & BLL 85 ST $63 \mathrm{~Kb} 136$ & Templo & $b$ & $b-p$ & 10 & N.D. & & A. 4 & 2 \\
\hline 32 & BIL 83 T V a 541 & Teatro & a & $b-p$ & 12 & N.D. & & & 2 \\
\hline 33 & BIL 83 TV a 660 & Teatro & a & p. ca & & N.D. & & A. 1.10 & 2 \\
\hline 34 & BIL SPI $1 H^{\prime} 56$ & Catas & & $b-p$ & 16 & N.D. & & A. 15 & 2 \\
\hline 35 & BIL SBI a 58 & Catas & a & $b-$ & 9 & N.D. & & A.3a & 2 \\
\hline 36 & BIL SP MB 37 & Cata & & $b-p$ & 13,1 & N.D. & & A.3a & 2 \\
\hline
\end{tabular}


VASOS CARENADOS Forma Abascal 4

\begin{tabular}{|c|c|c|c|c|c|c|c|c|c|}
\hline № & SIGLA & SECTOR & NIVEL & F. & $\mathrm{O} / \mathrm{cm}$. & FIGURA & C. PINT. & DECORACIÓN & PASTA \\
\hline 37 & BIL 82 ST 2 Q' c 158 & Templo & $c$ & $b-p$ & & N.D. & & A.2 & $4 b$ \\
\hline 38 & BIL 83 ST $2 Q^{\prime}$ c 158 & Templo & $c$ & $b-p$ & & N.D. & & & \\
\hline 39 & BIL 85 ST $14-16$ R-S b 2 & Tempio & $b$ & $p$. & & N.D. & & B.6 & $4 b$ \\
\hline 40 & BIL 85 ST $39-41$ VX 33 & Templo & & $b-p$ & 15 & N.D. & & A.14 & $4 b$ \\
\hline 41 & BIL 85 ST 41 N'O' 991 & Templo & & $b-p$ & & N.D. & & A. 1 & $4 b$ \\
\hline 42 & BIL 84 ST-T III $67 \mathrm{Jb} 8$ & Teatro $F$. & $b$ & $b-p$ & 17 & N.D. & & A.1 & $4 b$ \\
\hline 43 & BIL 84 ST-T III $71 \mathrm{G}$ a 14 & $"$ & a & $b-p$ & 16 & 12.41 & & A.1 & $4 b$ \\
\hline 44 & BIL 82 T III 1254 & Teatro & & $b-p$ & & N.D. & & A. 1 & $4 b$ \\
\hline 45 & BIL Cl 1192 & Catas & & $b-p$ & 15 & 12.38 & & A.2.14 & $4 b$ \\
\hline 46 & BIL 82 CIII 34-36-38 ABC k & $k$ k $1808 / 1810$ & & $b-p$ & 11 & 11.37 & & A.16 & $4 b$ \\
\hline 47 & BIL 82 CIII 34-36-38 ABC n & n 2517 & & $b-p$ & 12 & N.D. & & A.4 & $4 b$ \\
\hline 48 & BIL 82 Cll 1 CDE c 18 & Viviendas & $c$ & $b-p$ & 13 & 12.39 & & & $4 b$ \\
\hline 49 & BIL 82 Cll 1-2 F c 514 & Viviendas & $c$ & b-p & & 12.40 & & A.1.2.14 & $4 b$ \\
\hline
\end{tabular}

VASOS CARENADOS Forma Arcóbriga 5

\begin{tabular}{lccccccccc}
\hline № & SIGLA & SECTOR & NIVEL & F. & O/cm. & FIGURA & C. PINT. & DECORACIÓN & PASTA \\
\hline 50 & BIL 85 ST 37-39 P'Q' b 10/ Templo & b & b-p & 18 & 11.36 & & A.17 \\
& BIL 85 ST 41 N'O' 167 & ca & & & & & 2 \\
\hline
\end{tabular}

TAZAS CARENADAS-Imitación Mayet XLVIII

\begin{tabular}{|c|c|c|c|c|c|c|c|c|c|}
\hline № & SIGLA & SECTOR & NIVEL & $\mathrm{F}$. & $\mathrm{O} / \mathrm{cm}$. & FIGURA & C. PINT. & DECORACIÓN & PASTA \\
\hline 51 & BIL 85 ST 3-5 S e 17 & Templo & e & p. & 7 & N.D. & & A.3 b & $4 b$ \\
\hline 52 & BIL 85 ST 35-37 ABC 148 & Templo & & $p$ & & N.D. & & A. 18.20 & 2 \\
\hline 53 & BIL 85 ST $35-37$ T-U C 109 & 9 Templo & & $b-p$ & 9,1 & N.D. & & A.3b. $7 a$ & 2 \\
\hline 54 & BIL 85 ST $35-37$ T.U C 200 & O Templo & $c$ & $b-p$ & 8 & N.D. & rojo & A.7a & 2 \\
\hline 55 & BIL. 85 ST 48-50 O'P' b 1 & Templo & b & p. & & N.D. & & B. 2.7 & 2 \\
\hline 56 & BIL 83 TV a 357 & Teatro & a & $b-p$ & 10 & N.D. & & A. 1 B. 4 & 2 \\
\hline 57 & BIL 79 BII E-10 57 & Termas & & $b-p$ & 7,5 & N.D. & & Aç11 & $4 b$ \\
\hline 58 & BIL 79 BII I-10 43 & Termas & & $f-p$ & 4,5 & N.D. & rojo & A. 8.15 & 2 \\
\hline 59 & BIL 82 CIII 34-36-38 ABC & e 738 Cat. & e & p. & 11 & 13.45 & & A.22 & 2 \\
\hline 60 & $\begin{array}{l}\text { BIL } 82 \text { CIII 34-36-38 ABC } \\
\text { k } 1809\end{array}$ & j 1408/C. & $i / k$ & $b-p$ & 10 & 13.43 & & A.7a.20 & 2 \\
\hline 61 & BIL 82 Clil $34-36-38 \mathrm{ABC}$ & $\mathrm{k} 1816 \mathrm{Ca}$ & $k$ & p. & & N.D. & & A. 12.20 & 2 \\
\hline 62 & BIL BCl 154 & jiendas & & p. & & 13.44 & rojo & A.12.18.20 & 2 \\
\hline 63 & $B|L S P||A|$ & urall & & $b-p$ & 11 & 13.42 & & A. $7 b .12 .20$ B. 4 & 2 \\
\hline 64 & BIL SP $\mid 1 H^{\prime} 57$ & Iuralla & & p. & 11 & 13.46 & & A.22 & 2 \\
\hline 65 & BIL 78 SB II c 29 & as: barranco & & $b \cdot p$ & 12 & N.D. & & A.7a.12.15.20 & 2 \\
\hline
\end{tabular}


COPAS CON PIE

\begin{tabular}{|c|c|c|c|c|c|c|c|c|c|}
\hline № & SIGLA & SECTOR & NIVEL & F. & $\mathrm{O} / \mathrm{cm}$ & FIGURA & C. PINT. & DECORACIÓN & PASTA \\
\hline 66 & $\begin{array}{l}\text { BIL } 83 \text { ST 46-48-50 D'E'F' } \\
\text { a } 6\end{array}$ & Templo & a & $b-p$ & 14 & 6.18 & & A. 1 & 3 \\
\hline 67 & BLL 85 ST $3-5$ S e 56 & Templo & e & $b-p$ & 15 & N.D. & rojo & A. 1 & 3 \\
\hline 68 & BIL 85 ST 7-9 R.S d 140 & Templo & $d$ & base & 15 & N.D. & rojo & A.1 & 3 \\
\hline 69 & BIL 85 ST 13-15 N'O' b 35 & Templo & $b$ & pie & & 8.27 & & A. 10.14 & $4 b$ \\
\hline 70 & BIL 85 ST 19-21 O'P' 21 & Templo & & $b-p$ & 14 & 7.24 & & A. 1 & $4 b$ \\
\hline 71 & BIL 85 ST $22.24 N^{\prime}$ b 7 & Templo & $b$ & base & 13 & 9.31 & & A. 1 & 3 \\
\hline 72 & BIL 85 ST 29-31 O'P' 6 & Templo & & $b-p$ & 13 & 6.19 & & A. 1 & 3 \\
\hline 73 & BIL 85 ST 29-31 P'Q' c 99 & Templo & $c$ & $b-p$ & 14,2 & 6.21 & & A. 1 & 3 \\
\hline 74 & BIL 84 ST-T III 41 T c 53 & Teatro-Foro & $\mathrm{C}$ & $b-p$ & 18,5 & 8.26 & & A.7c & 4 \\
\hline 75 & $\mathrm{BIL} T \mathrm{TI} \mathrm{B}^{\prime} 111$ & Teatro & & $b-p$ & 12,7 & 7.22 & & A. 1 & 3 \\
\hline 76 & BIL TI 5 C' 314 & Teatro & & base & 13 & 9.29 & & A. 1 & 3 \\
\hline 77 & BIL 83 T III 262 & Teatro & & base & 13 & 9.30 & & A.1 & 3 \\
\hline 78 & BIL 79 B\|I I 1059 & Termas & & pie & & N.D. & & A. 1 & 3 \\
\hline 79 & BIL 79 BII $4 J 2$ & Termas & & pie & & N.D. & & A.1 & 3 \\
\hline 80 & BIL 79 BII 18 F 39 & Termas & c. & & & N.D. & & A.7c & 3 \\
\hline 81 & BIL BC $15 \mathrm{E} 3$ & Viviendas & & $b-p$ & 10 & 7.25 & & A.1 & 3 \\
\hline 82 & BIL SBI 4A 298 & Catas & & $b-p$ & 14,1 & 7.23 & & & 3 \\
\hline 83 & BIL 78 SB II A 18 & Catas & & $b-p$ & 13 & 6.20 & & A.1 & 3 \\
\hline 84 & BIL SPI 1H'301 & Muralla S. & & $b \cdot p$ & 15,5 & N.D. & & A. 1 & 3 \\
\hline 85 & BIL 82 CII A2 8-10 4 & Viviendas & & base & 16 & 9.32 & & A. 1 & 3 \\
\hline 86 & BIL $82 \mathrm{Cll} 14-16 \mathrm{Y}-\mathrm{Z}$ a 6 & Viviendas & $\mathrm{a}$ & base & 16 & 8.28 & & A. 1 & 3 \\
\hline
\end{tabular}

BOTELLAS Forma Arcóbriga 5

\begin{tabular}{lllllllllc}
\hline № & SIGLA & SECTOR & NIVEL & F. & O/cm. & FIGURA & C. PINT. & DECORACIÓN & PASTA \\
\hline 87 & BIL 82 CII 7 CD c 22 & Viviendas & c & boca & 6,2 & 14.51 & A.3b & 2 \\
88 & BIL 82 CII 9 A c 1 & Viviendas & c & boca 7 & 14.50 & A.3b & 2 \\
\hline
\end{tabular}

BOTELLAS Forma Arcóbriga 6

\begin{tabular}{lllllllllc}
\hline No & \multicolumn{1}{c}{ SIGLA } & SECTOR & NIVEL & F. & O/cm. & FIGURA & C. PINT. & DECORACIÓN & PASTA \\
\hline 89 & BLL 81 ST 49-51 OP c 20 & Templo & c & boca & 9,1 & 14.54 & & & 2 \\
90 & BIL Cl (1975) 1529 & Catas & & boca & N.D. & & & 2 \\
91 & BIL Cl 1951/1955 & Catas & & boca & 8,7 & 14.48 & & A.3b & 2 \\
\hline
\end{tabular}

BOTELLAS Forma indeterminada

\begin{tabular}{|c|c|c|c|c|c|c|c|c|c|}
\hline № & SIGLA & SECTOR & NIVEL & F. & $\mathrm{O} / \mathrm{cm}$. & FIGURA & C. PINT. & DECORACIÓN & PASTA \\
\hline 92 & BIL 84 ST $48-50$ I-J c 58 & Templo & c & cuello & & 15.56 & & A. 1 & 2 \\
\hline 93 & BIL 85 ST 63 O'P' 14 & Templo & c & cuello & & 17.63 & & & 2 \\
\hline 94 & BIL 82 CII Y-Z 20-22 44 & Viviendas & & $b-p$ & & 15.57 & & A. $3 \mathrm{~b} .4$ & 2 \\
\hline 95 & BIL 82 CII 1-2 F c 161 & Viviendas & c & $b-c$ & 5 & 14.49 & & A.3b & 2 \\
\hline 96 & BIL 82 CII 3-5 F C 101 & Viviendas & $\mathrm{c}$ & cuello & & 15.55 & & A.3b. 4 & 2 \\
\hline
\end{tabular}


GARRAFA

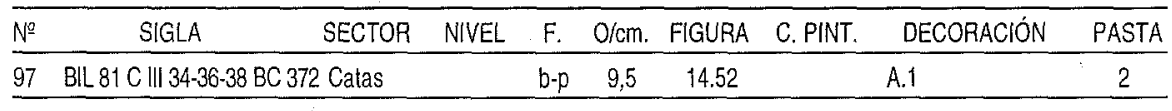

JARRA BORDE MOLDURADO

\begin{tabular}{cccccccccc}
\hline$N^{0}$ & SIGLA & SECTOR & NIVEL & F. & O/cm. FIGURA & C. PINT. & DECORACIÓN & PASTA \\
\hline 98 & BIL 85 ST 18-20 S c 6 & Templo & $c$ & b-p & 10 & 14.53 & & A.1 & 2 \\
\hline
\end{tabular}

BOTELLAS/JARRAS Forma Indeterminada

\begin{tabular}{|c|c|c|c|c|c|c|c|c|c|}
\hline № & SIGLA & SECTOR & NIVEL & $\mathrm{F}$. & $\mathrm{O} / \mathrm{cm}$ & FIGURA & C. PINT. & DECORACIÓN & PASTA \\
\hline 99 & BLL 83 ST 15 Qb 7 & Templo & $b$ & $\mathrm{cu}$ & & 25.94 & & A.12 & $4 b$ \\
\hline 100 & BIL 83 ST $27 \mathrm{~S} \mathrm{~d} 74$ & Templo & $d$ & p. & & N.D. & & & 2 \\
\hline 101 & BIL 84 ST 42 L-K b 12 & Templo & $b$ & & & N.D. & & A.4 & 2 \\
\hline 102 & BIL 84 ST $52-54$ FGH c 107 & Templo & c & $c-p$ & & N.D. & rojo & & 2 \\
\hline 103 & BIL 85 ST 7.9 S e 184 & Templo & e & & & 17.68 & & B.3.6 & 2 \\
\hline 104 & EIL 85 ST 10-12 S c 22 & Templo & $c$ & p. & & 16.61 & rojo & A.6b & 2 \\
\hline 105 & BIL 85 ST $11-13$ R-S b $20^{\circ}$ & Templo & $b$ & p. & & 16.59 & & A.1.4 & 2 \\
\hline 106 & BIL 85 ST $13.15 P^{\prime} Q^{\prime}$ c 232 & Templo & $\mathrm{c}$ & $c-p$ & & 24.90 & & & - \\
\hline 107 & BIL. 85 ST 28-30 MN 27 & Templo & - & $p$ & & 24.91 & & & $-(+)$ \\
\hline 108 & $\begin{array}{l}\text { BIL } 85 \text { ST } 31-33 \text { U e } 18 / \\
35-37 \text { T } \cup \text { b } 263 / \\
27-29 \text { T-U e 104-105 }\end{array}$ & Templo & $e / b$ & p. & 25.92 & 25.95 & & A6a.12 & $\begin{array}{l}4 b \\
4 b \\
4 b\end{array}$ \\
\hline $10 \mathrm{~s}$ & BIL 85 ST 48-50 $\mathrm{M}^{\prime} d 1$ & Tempio & $d$ & $\mathrm{p}$ & & N.D. & & A.8.10 & 2 \\
\hline 110 & BIL 85 ST 49.51 OP C 36 & Templo & $c$ & p. & & N.D. & & A.4 & 2 \\
\hline 111 & BIL 84 ST-TIII 691 c 16 & TeatroF & $c$ & p. & & N.D. & & & 2 \\
\hline 112 & BIL $82 \mathrm{~T}$ III 1246 & Teatro & & p-ca & & 25.96 & & 8.1 & $4 b$ \\
\hline 113 & BIL 82 T III 1495 & Teatro & & p. & & 25.97 & & A.2.21 & $4 b$ \\
\hline 114 & BIL 83 T III 149 & Teatro & & p. & & N.D. & & A. 8 & 2 \\
\hline 115 & BIL 83 TVIV 106 b 9 & Teatro & $b$ & $p$ & & 17.62 & & B.1 & 2 \\
\hline 116 & BIL 83 T VI W 103 c 27 & Teatro & $c$ & $\mathrm{p}$ & & N.D. & rojo & A.6b & 2 \\
\hline 117 & BIL SP | 1-B 101 & Muraila S & & p. & & N.D. & & A.bb & 2 \\
\hline 118 & BIL BC \|I $1 A^{\prime} 56 / 2 A^{\prime} 24$ & Termas & & & & N.D. & & A. 4 & 2 \\
\hline 119 & $B I L B C \| 2 A^{\prime} 350 / 2 B 57$ & Termas & & p. & & 17.65 & & A.2.6a.21. C.3 & $4 b$ \\
\hline 120 & BIL 79 BIII $1080 / 86$ & Termas & & & & 17.69 & & A.3b. 11 & 2 \\
\hline 121 & BIL 84 ST K 40 b 84 & Templo & $b$ & p. & & N.D. & & & 2 \\
\hline 122 & BIL CH Cl 66 & Cisterna & & p. & & N.D. & rojo & A.1.4 & 2 \\
\hline
\end{tabular}

(') Cerámicas Bajo-imperiales. 


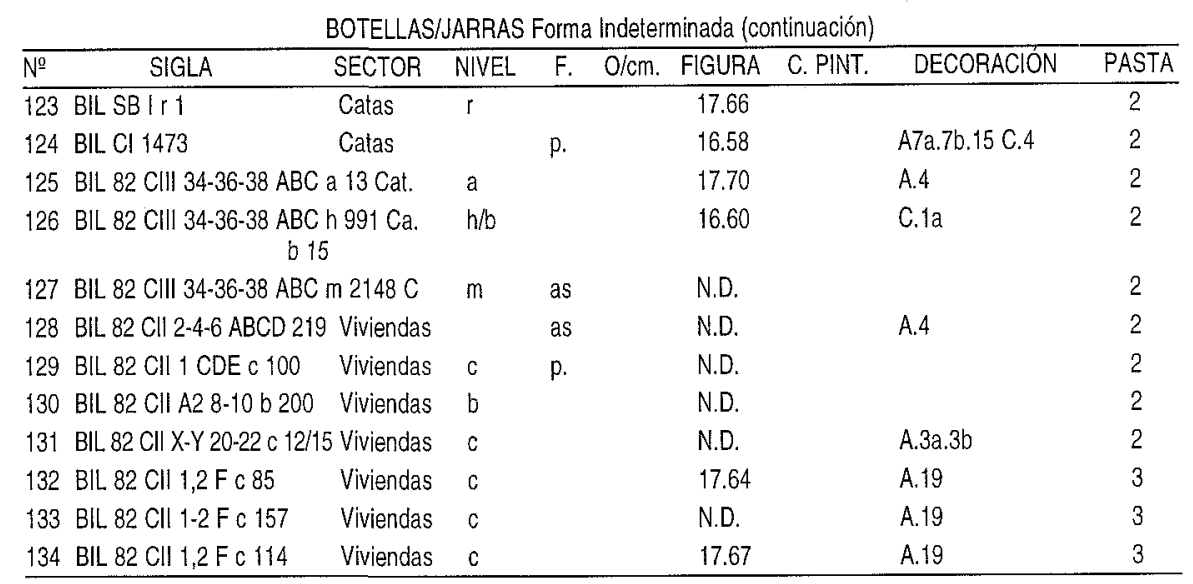

KALATHOS

\begin{tabular}{|c|c|c|c|c|c|c|c|c|}
\hline SIGLA & SECTOR & NIVEL & F. & $\mathrm{O} / \mathrm{cm}$ & FIGURA & C. PINT. & DECORACION & PASTA \\
\hline 135 BIL 83 ST D'36 b 31 & Templo & $\mathrm{b}$ & $b-p$ & 25 & 23.85 & & A.1.20 & 3 \\
\hline 136 BLL 85 ST $47-49 P^{\prime} Q^{\prime} \mathrm{C} 27$ & Templo & c & $b-p$ & 18 & 22.82 & & & 3 \\
\hline 137 BIL 79 Cll-C1-2 & Viviendas & & $b-p$ & 15 & 22.84 & & A. 1 & 3 \\
\hline 138 BIL SP I $1 H^{\prime} 200$ & Muralla S. & & $b-p$ & 21 & 23.86 & & A.1 & 3 \\
\hline 139 BIL C.S. 624 & $\begin{array}{l}\text { Colección } \\
\text { Samitier }\end{array}$ & & $b \cdot p$ & 19 & 22.83 & & A. 4 & 3 \\
\hline
\end{tabular}

ORZAS Forma Arcóbriga 1

\begin{tabular}{|c|c|c|c|c|c|c|c|c|c|}
\hline № & SIGLA & SECTOR & NIVEL & F. & $\mathrm{O} / \mathrm{cm}$. & FIGURA & C. PINT. & DECORACION & PASTA \\
\hline 140 & $\begin{array}{l}\text { BIL } 82 \text { Cll } 20-22 \text { X-Y a } 4 \\
26 / 28 \text { X } 6-7-8 \\
\text { A2-X } 10 \text { b } 81\end{array}$ & Viviendas & $\begin{array}{l}a \\
1 \\
b\end{array}$ & $\begin{array}{l}b-p \\
y \text { as }\end{array}$ & 23 & 18.71 & & A.2.3b & 2 \\
\hline 141 & BIL 85 ST 56-58 N-O b, 62 & Templo & $b$ & $b-p$ as & s 22 & 18.73 & & A. 4 & 3 \\
\hline 142 & BIL 83 TV a 637 & Teatro & $\mathrm{a}$ & b-p & & & & A. 1 & 2 \\
\hline 143 & BIL 78 BII 5 FG 1 & Termas & & $b-p$ & 23,4 & 18.72 & & A. 1 & 2 \\
\hline
\end{tabular}

ORZAS Forma Arcóbriga 2

\begin{tabular}{|c|c|c|c|c|c|c|c|c|}
\hline № & SIGLA & SECTOR & NIVEL & $F$. & $\mathrm{O} / \mathrm{cm}$ & FIGURA $\quad$ C. PINT. & DECORACION & PASTA \\
\hline 144 & BIL 82 ST 43-45 D'E' 430 & Templo & & $b \cdot p$ & 18 & N.D. & A.1 & 3 \\
\hline 145 & BIL 83 ST 6-8 O'P'Q'b 84 & Templo & b & $b-p$ & 20,2 & N.D. & A. 1 & 3 \\
\hline 146 & BIL 85 ST $33 P^{\prime} Q^{\prime} c 28$ bis & Templo & $c$ & b-p & 16 & N.D. & & 3 \\
\hline 147 & BIL BC $\| 2 A^{\prime} 2$ & Termas & & $b-p$ & 17 & N.D. & A. 1 & 3 \\
\hline 148 & BIL 78 BII A-4 15 & Termas & OBSE & $\begin{array}{l}\text { b-p } \\
\text { VACl }\end{array}$ & $\begin{array}{c}13 \\
\text { ONES. }\end{array}$ & $\begin{array}{l}19.75 \\
\text { - Grafito: AAI }\end{array}$ & A.1 & 2 \\
\hline 149 & BIL 79 BII $6 \mathrm{H}-14$ & Termas & & $b-p$ & 12 & 19.74 & A.1 & 2 \\
\hline 150 & BIL 82 Cll 34-36-38 ABC m & $\begin{array}{l}\text { 1 } 2158 \text { Catas } \\
\text { zona central }\end{array}$ & $\mathrm{m}$ & $b-p$ & 17 & N.D. & A. 1 & 2 \\
\hline 151 & BIL 82 Clll 34-36-38 ABC h & h 998 Catas & $\mathrm{h}$ & $b-p$ & 16,8 & N.D. & A.1 & 2 \\
\hline
\end{tabular}


ORZAS Forma Arcóbriga 3

\begin{tabular}{|c|c|c|c|c|c|c|c|c|c|}
\hline № & SIGLA & SECTOR & NIVEL & $\mathrm{F}$. & $\mathrm{O} / \mathrm{cm}$. & FIGURA & C. PINT. & DECORACIÓN & PASTA \\
\hline 152 & $\begin{array}{l}\text { BIL } 82 \text { CIII } 34-36-38 \\
\text { ABC } \cap 2662\end{array}$ & Catas Z.c. & $n$ & b-p & 16 & 20.78 & & A. 1 & 3 \\
\hline 153 & $\begin{array}{l}\text { BIL } 82 \text { CII } 34-36-38 \\
\text { ABC h } 99\end{array}$ & Catas z.c. & h & $b-p$ & 16,5 & 20.77 & & A.16 & 2 \\
\hline 154 & $\begin{array}{l}\text { BIL } 82 \text { CIII } 34-36-38 \\
\text { ABC k } 1800\end{array}$ & Catas z.C. & k & $p$ & 17,8 & 19.76 & & A.4 & 2 \\
\hline
\end{tabular}

ORZAS Forma Wattenberg 1963, 349

\begin{tabular}{llllllllll}
\hline No & SIGLA & SECTOR & NIVEL & F. & O/cm. & FIGURA & C. PINT. & DECORACIÓN & PASTA \\
\hline 155 & BIL.71 SPA b 18 & Casa Fort. & b & b-p & 14 & 21.79 & & A.4 & 2 \\
\hline
\end{tabular}

ORZAS Forma Tiermes tipo $1 \mathrm{~b}$

\begin{tabular}{lccccccccc}
\hline NN & SIGLA & SECTOR & NIVEL & F. & O/cm. & FIGURA & C. PINT. & DECORACIÓN & PASTA \\
\hline 156 & BIL 79 TI 3 B' 1005 & Teatro & - & b-p & 25 & 21.80 & & A.1 & \\
157 BIL SB I 4A 323 & Catas & - & b-p & & 21.81 & & & 2 \\
\hline
\end{tabular}

CANTIMPLORA Forma Abascal 26

\begin{tabular}{|c|c|c|c|c|c|c|c|c|c|}
\hline № & SIGLA & SECTOR & NIVEL & $\mathrm{F}$. & $\mathrm{O} / \mathrm{cm}$. & FIGURA & C. PINT. & DECORACIÓN & PASTA \\
\hline 158 & ST 13-15 & Templo & C & $b-p$ & & 24.87 & & & $-(t)$ \\
\hline
\end{tabular}

FORMA INEDITA-ORZA

\begin{tabular}{lccccccccc}
\hline № & SIGLA & SECTOR & NIVEL & F. & O/cm. & FIGURA & C. PINT. & DECORACIÓN & PASTA \\
\hline 159 BIL 83 ST 5 Q d 33 & Templo & d & b-p & 9 & 25.98 & & A.3b & \\
\hline
\end{tabular}

IMITACION MAYET III

\begin{tabular}{|c|c|c|c|c|c|c|c|c|}
\hline SIGLA & SECTOR & NIVEL & $\mathrm{F}$. & $\mathrm{O} / \mathrm{cm}$. & FIGURA & C. PINT. & DECORACIÓN & PASTA \\
\hline 160 BlL 83 T III 62-67 F2 b 1 & Teatro & $b$ & $b-p$ & 12 & N.D. & & A. 1 & 2 \\
\hline 161 BIL $B C \| 1 A 42$ & Termas & - & $b-p$ & 13 & N.D. & & A. 1 & 2 \\
\hline 162 BIL 81 C III 3.36 BC 374 & Catas & - & $b-p$ & 11 & N.D. & & A.1 & 2 \\
\hline $\begin{array}{l}163 \text { BlL CIII } 34-36-38 \text { ABC 0 } \\
2803\end{array}$ & Catas & 0 & $b-p$ & 6,5 & 24.88 & rojo & A. 1 & 2 \\
\hline
\end{tabular}

$\left(^{+}\right)$Cerámicas Bajo-imperiales. 

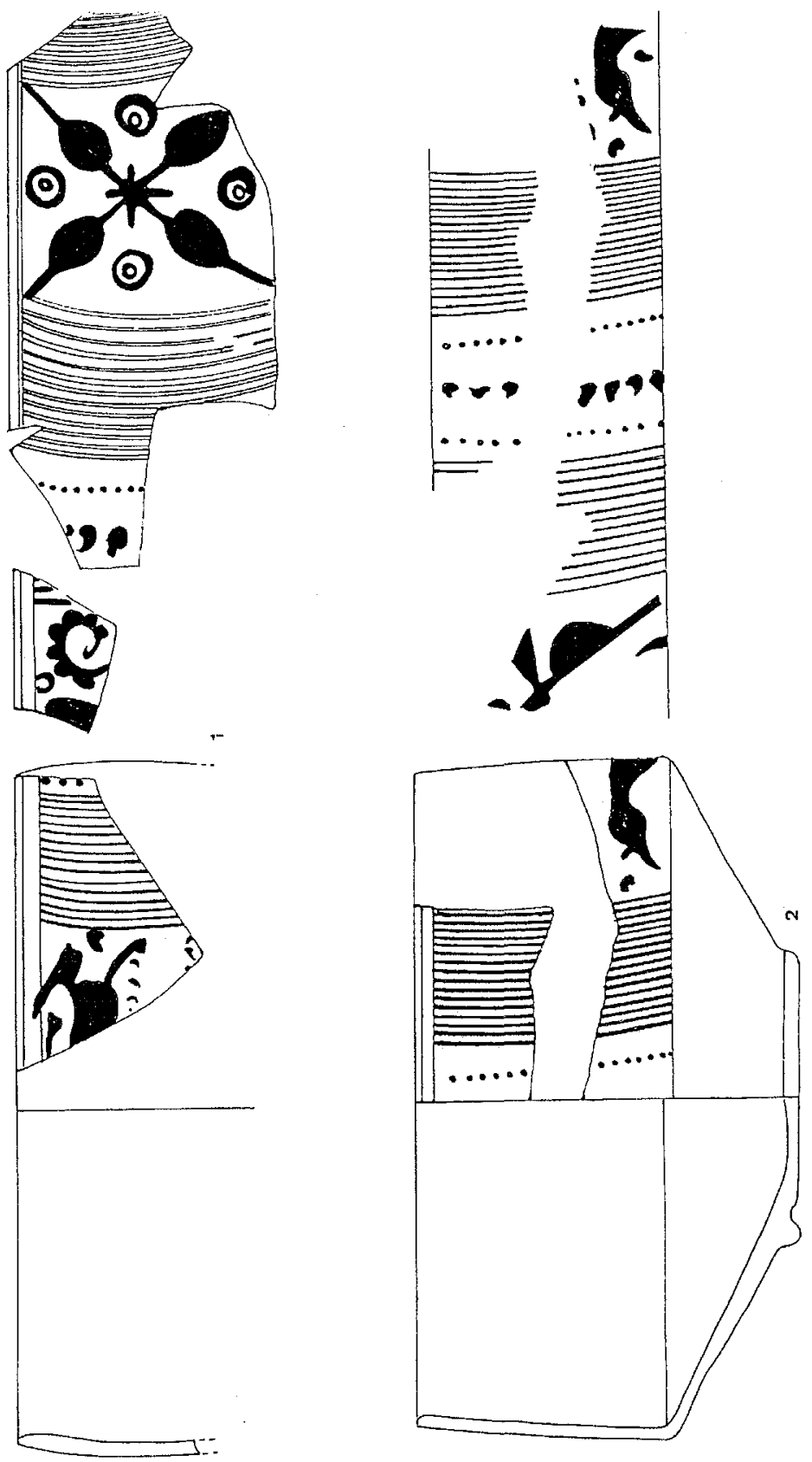

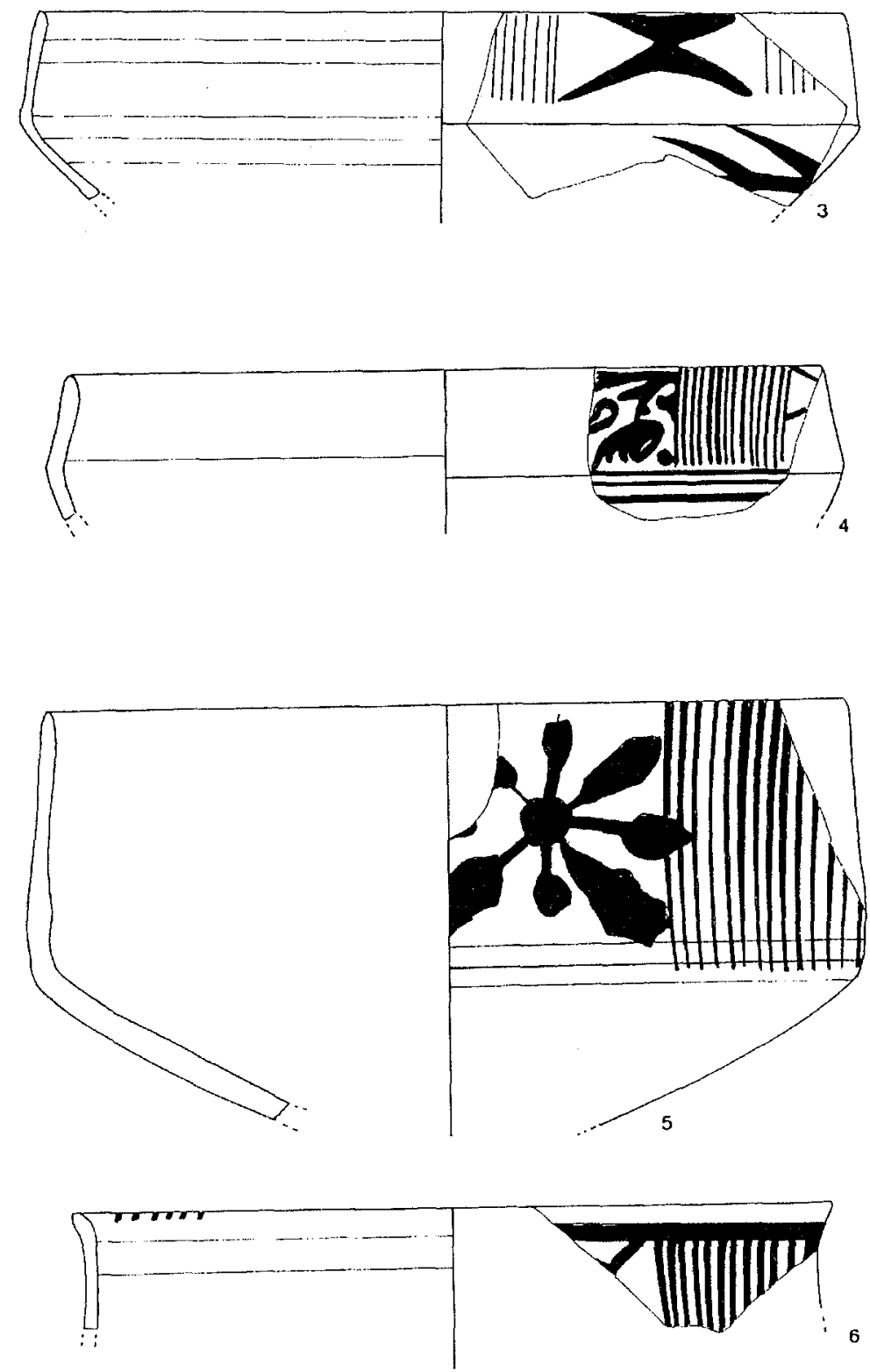

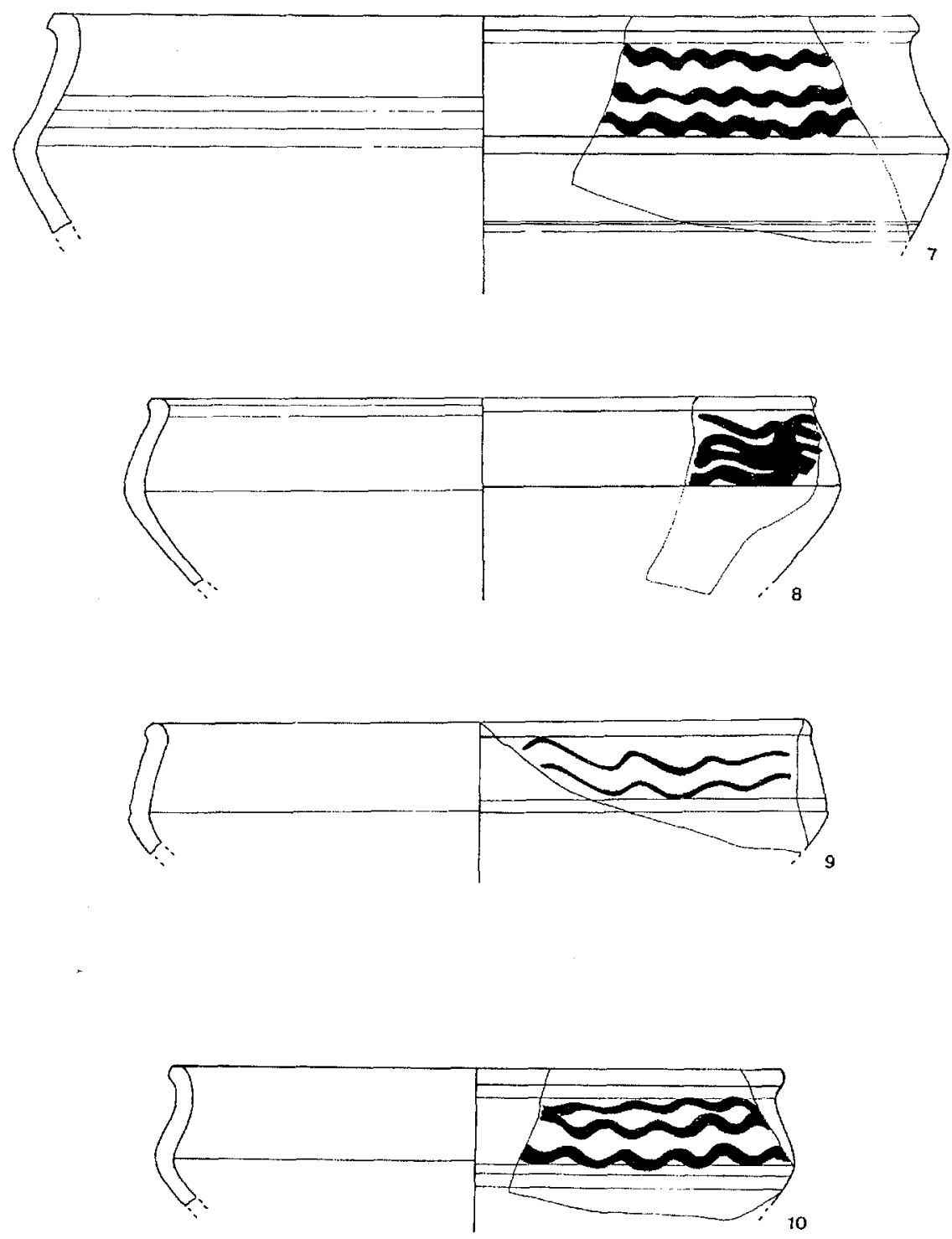

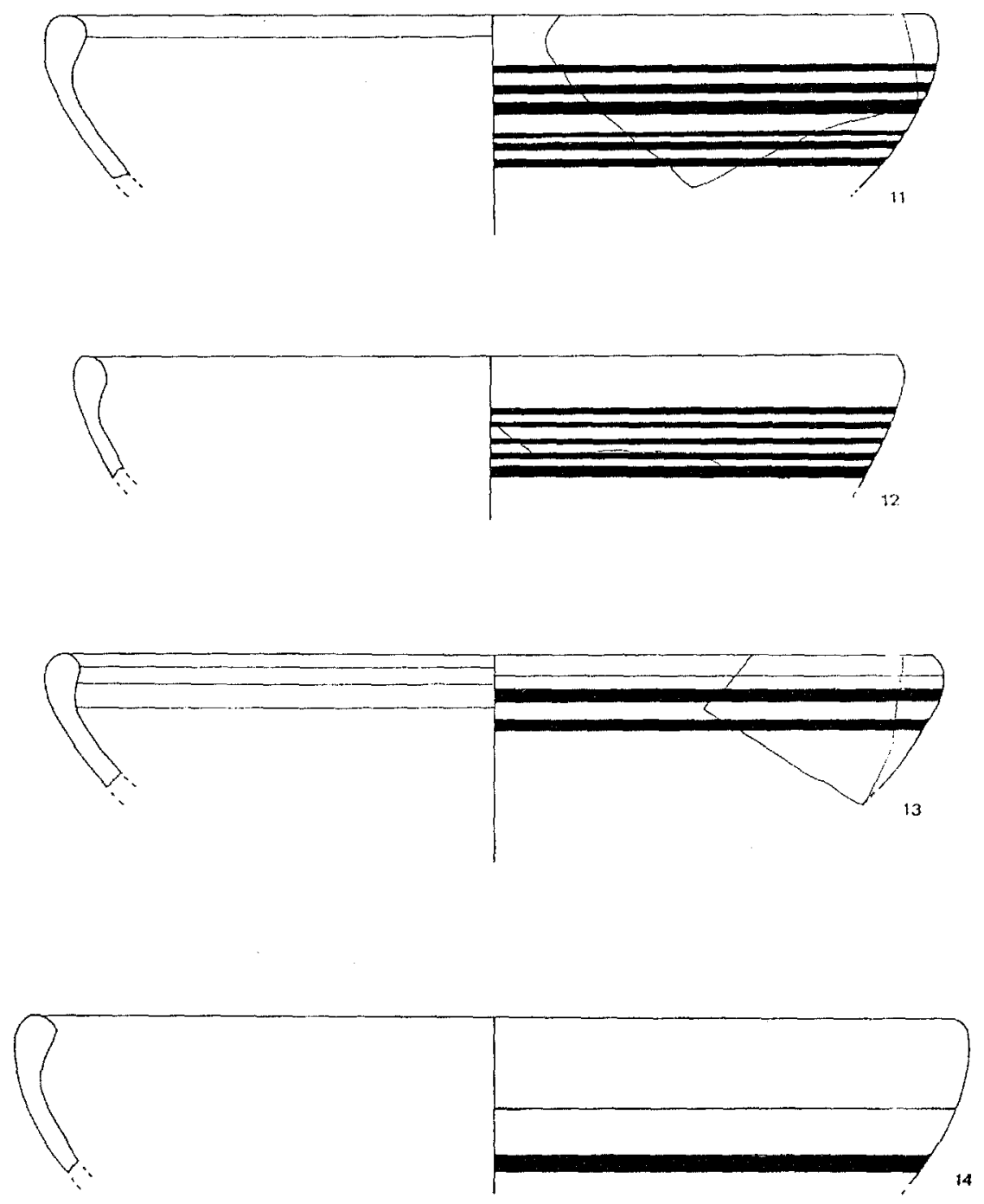

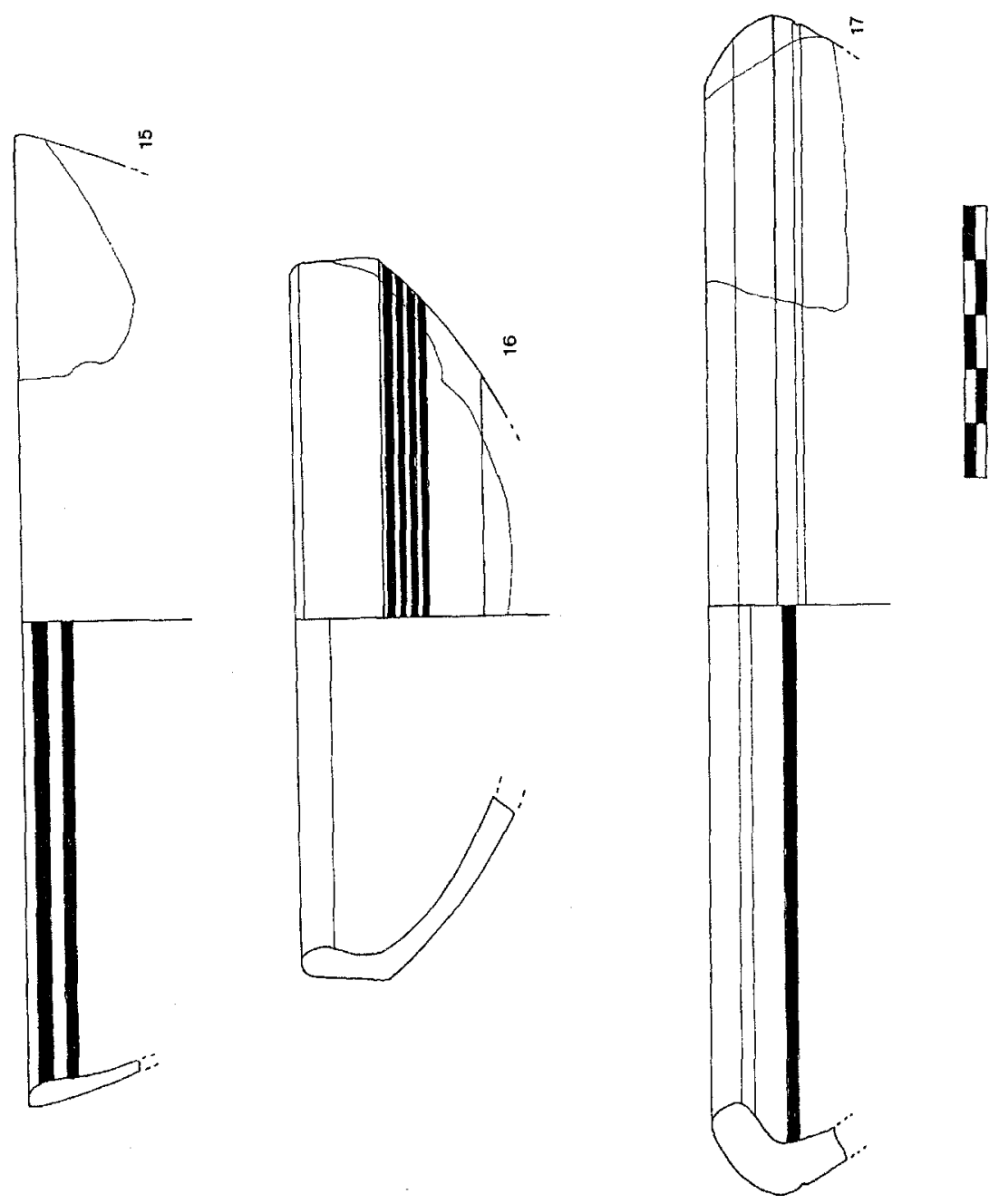

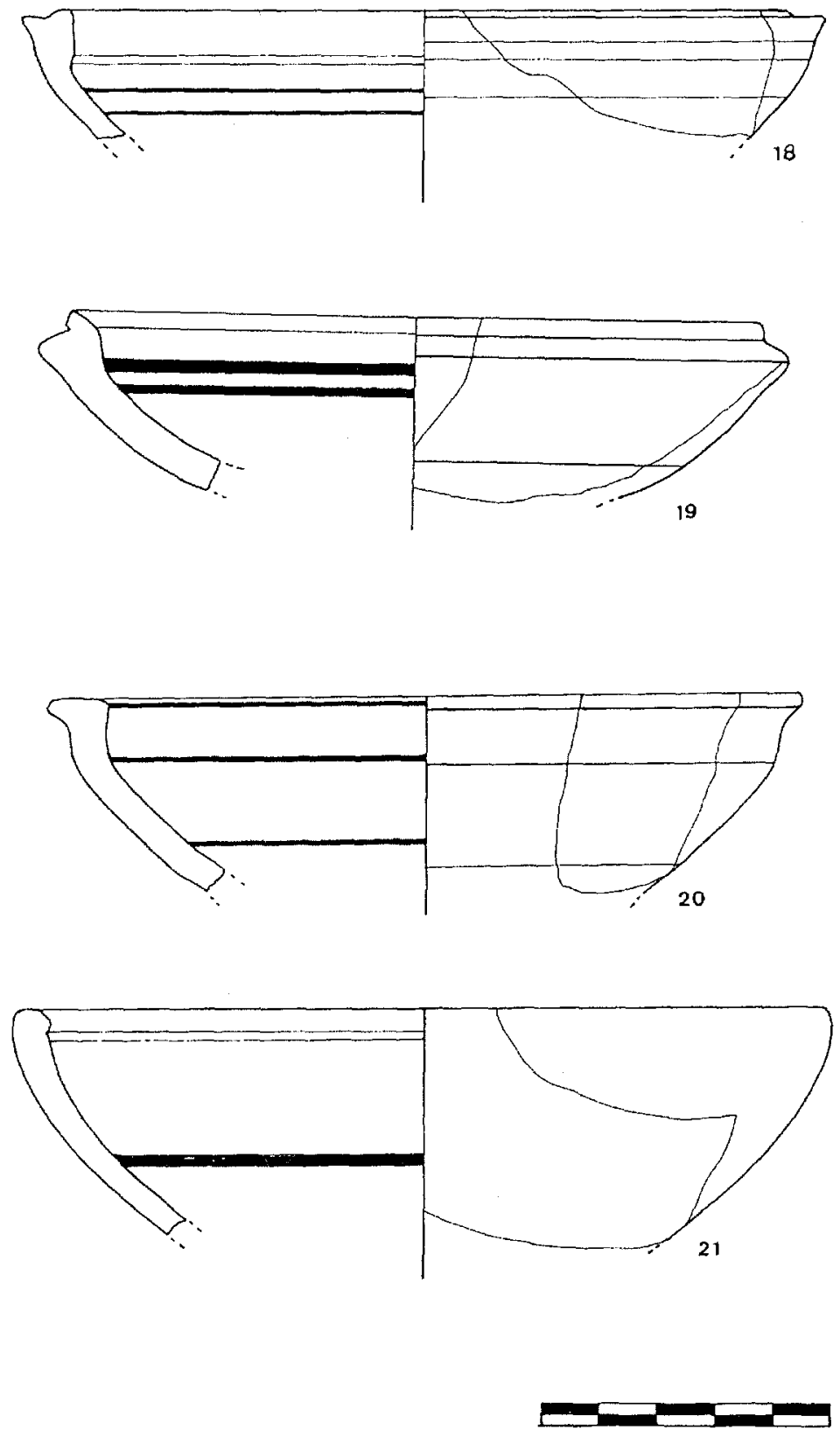

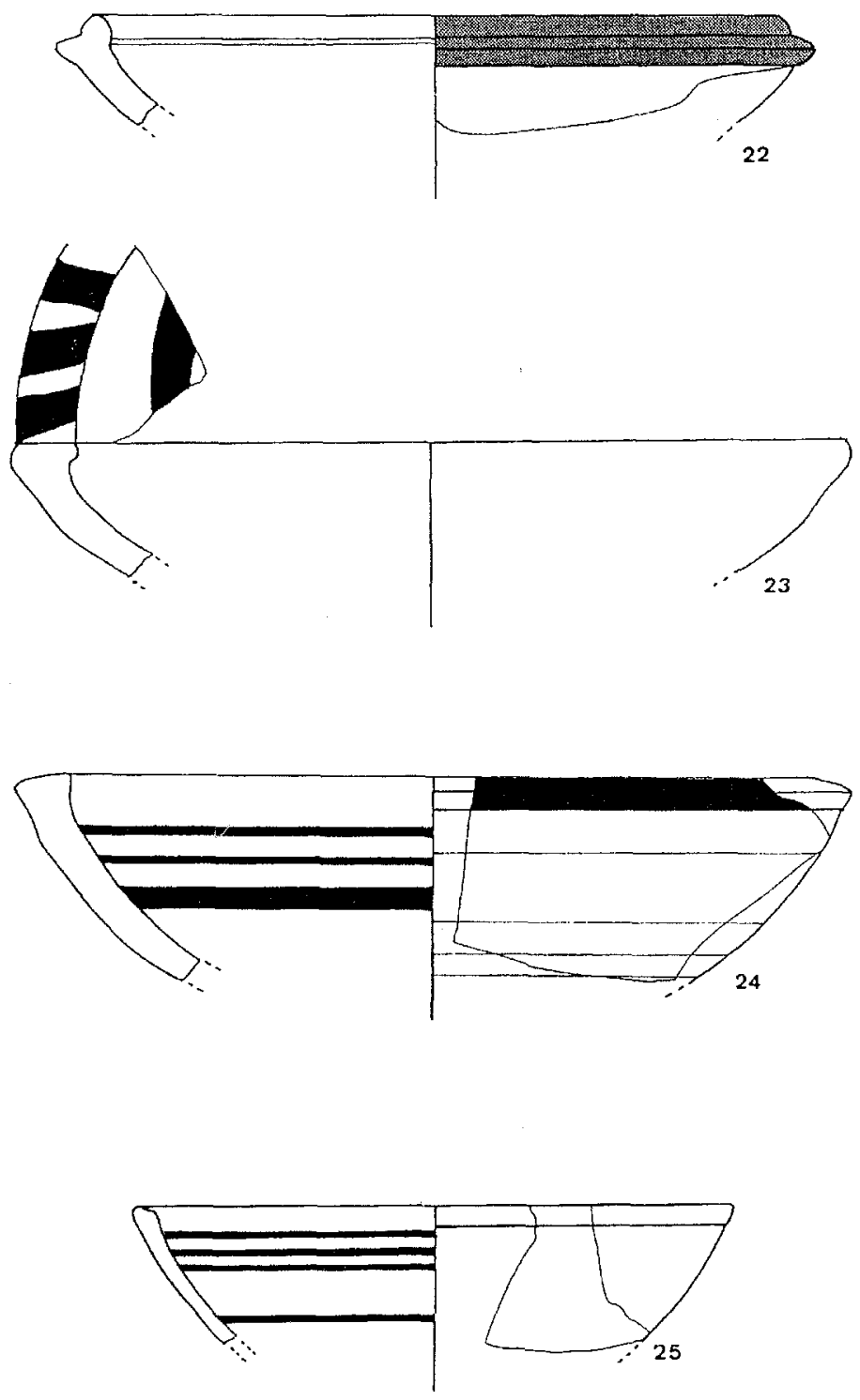

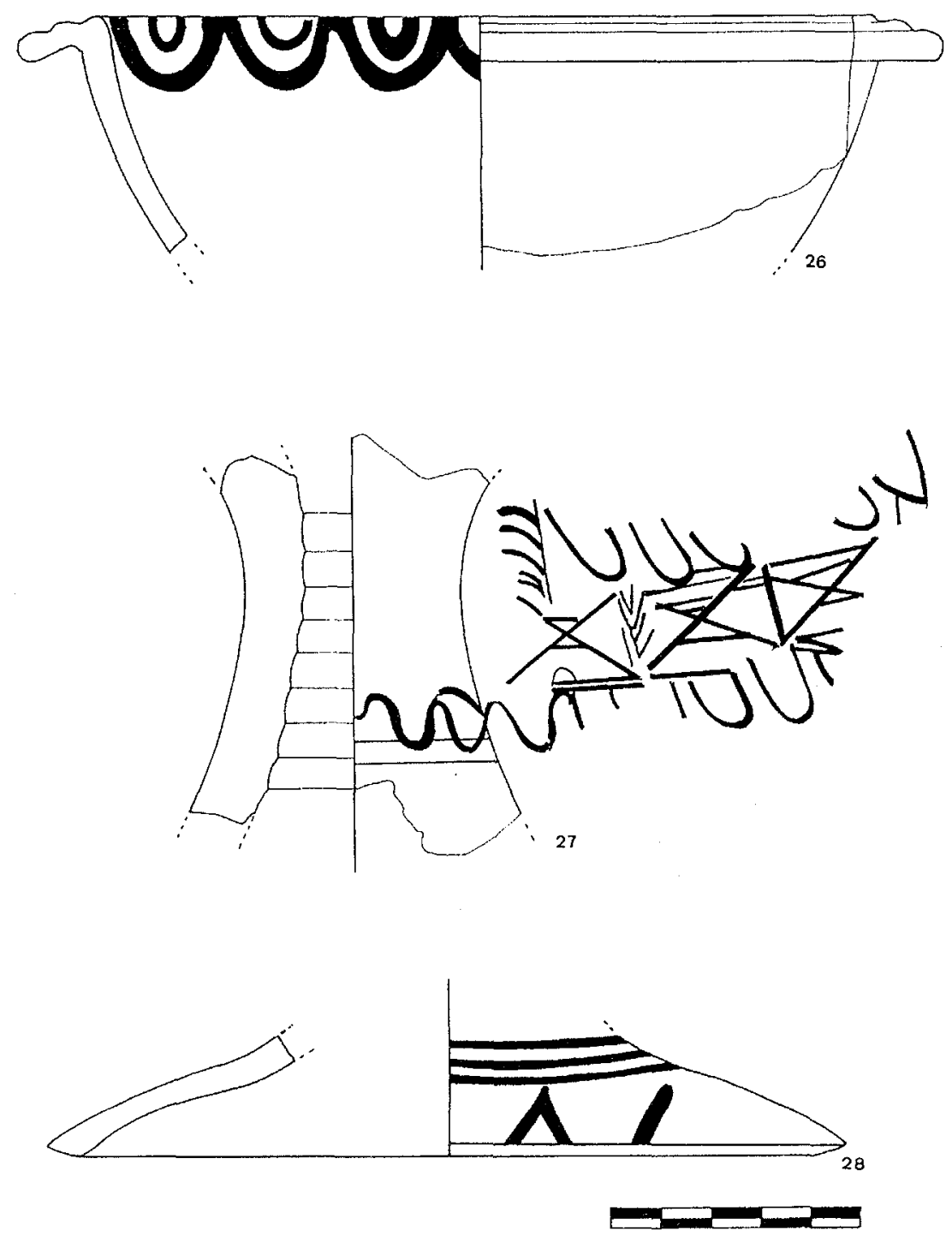

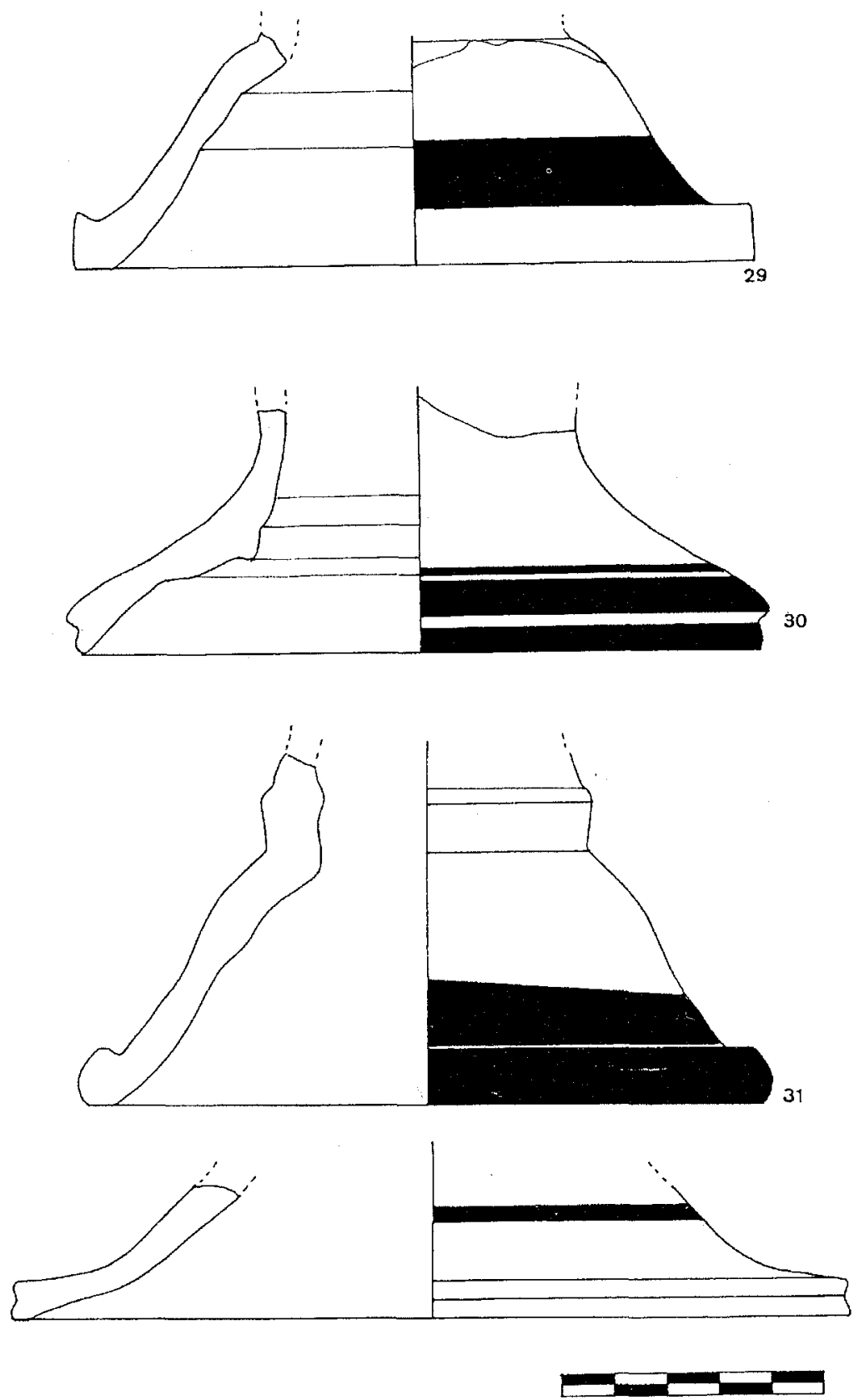

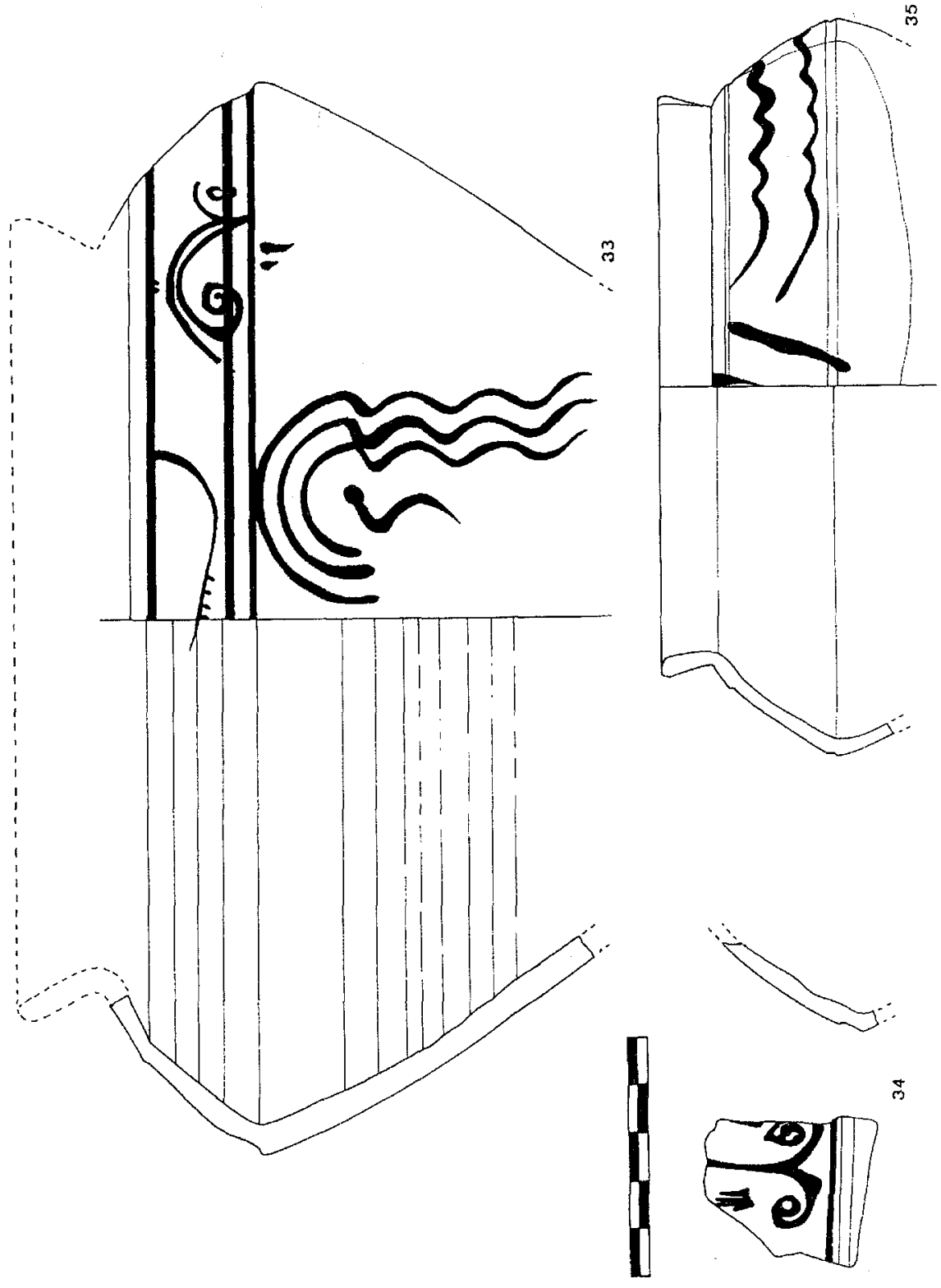

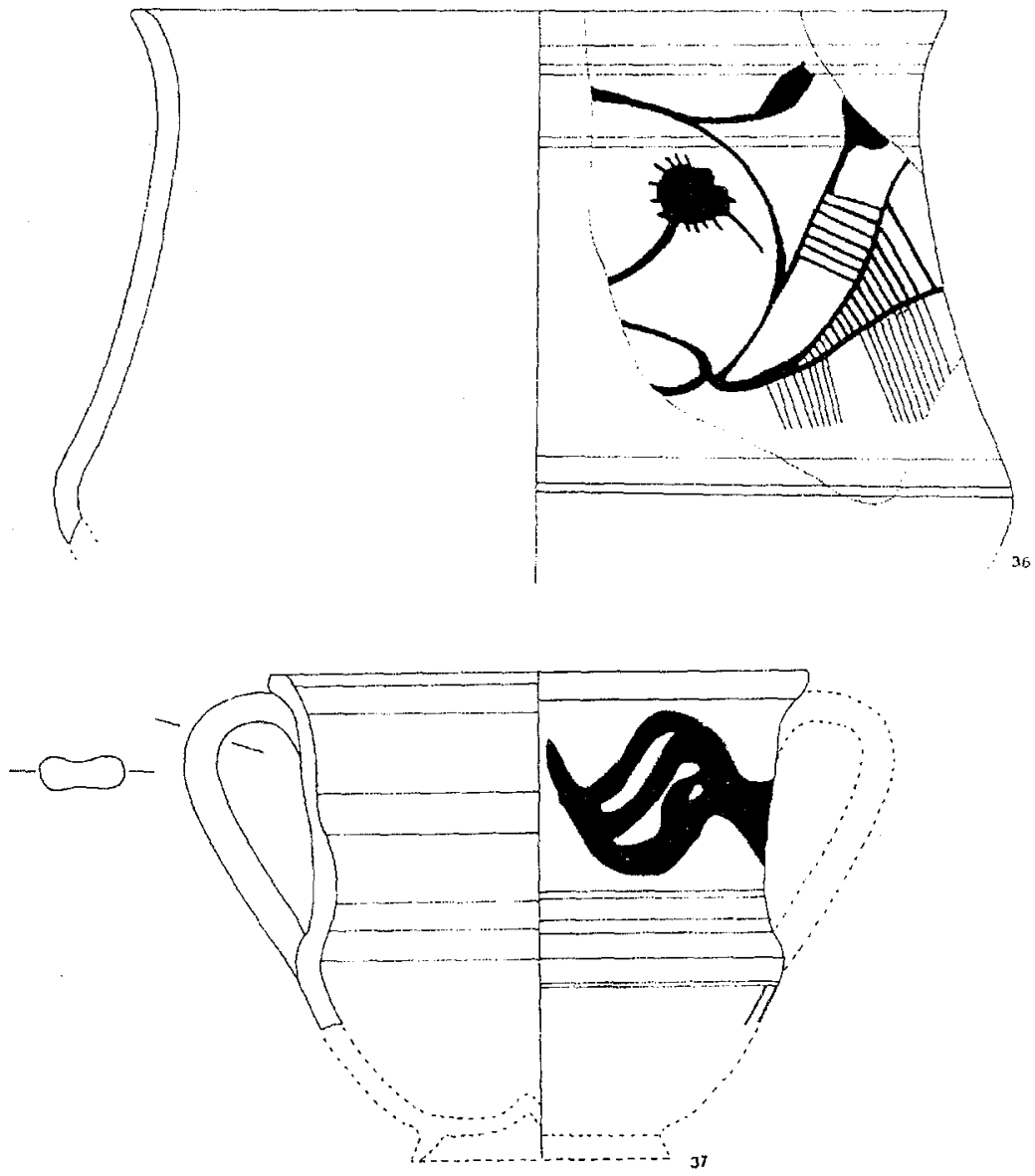

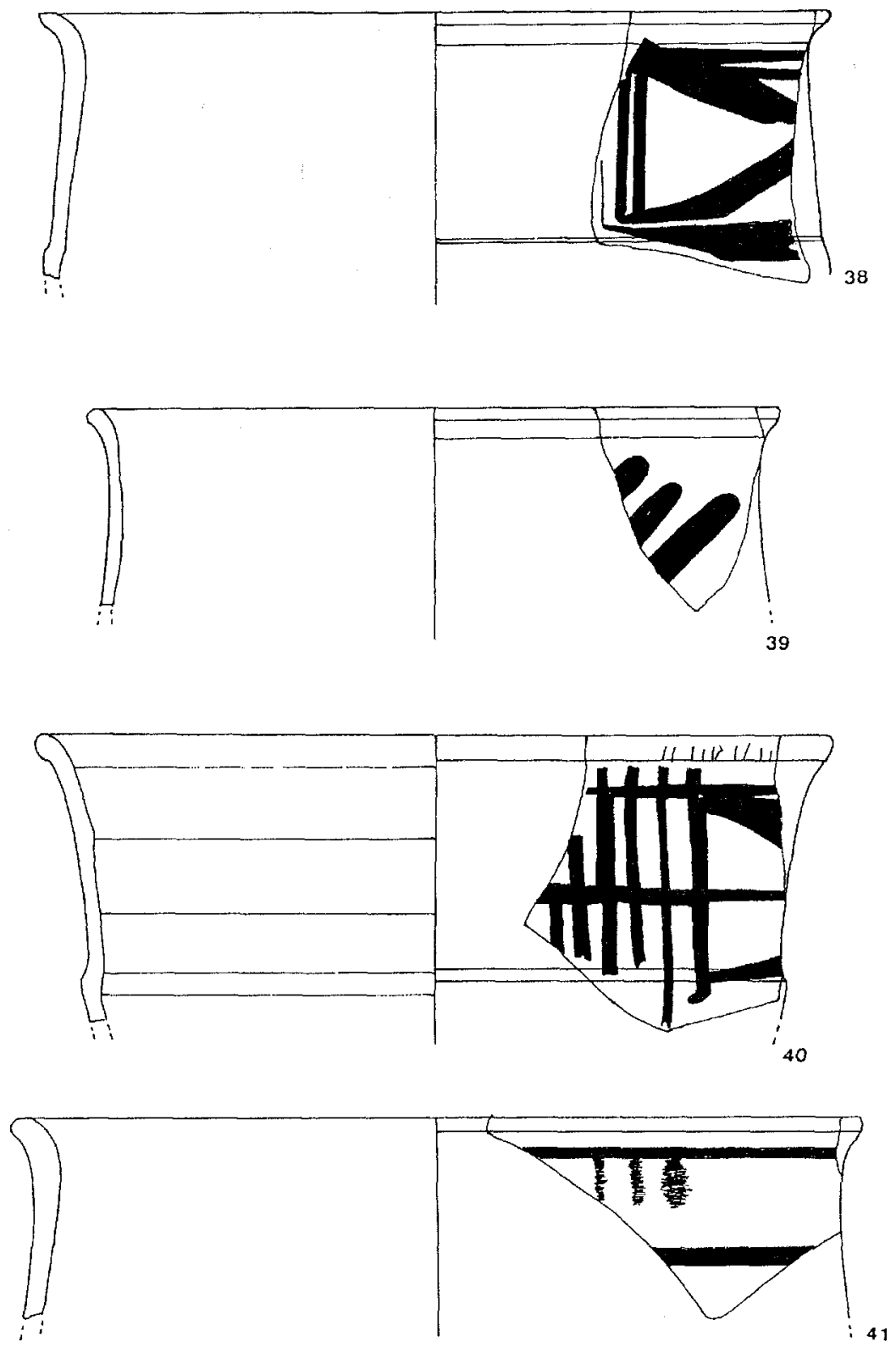

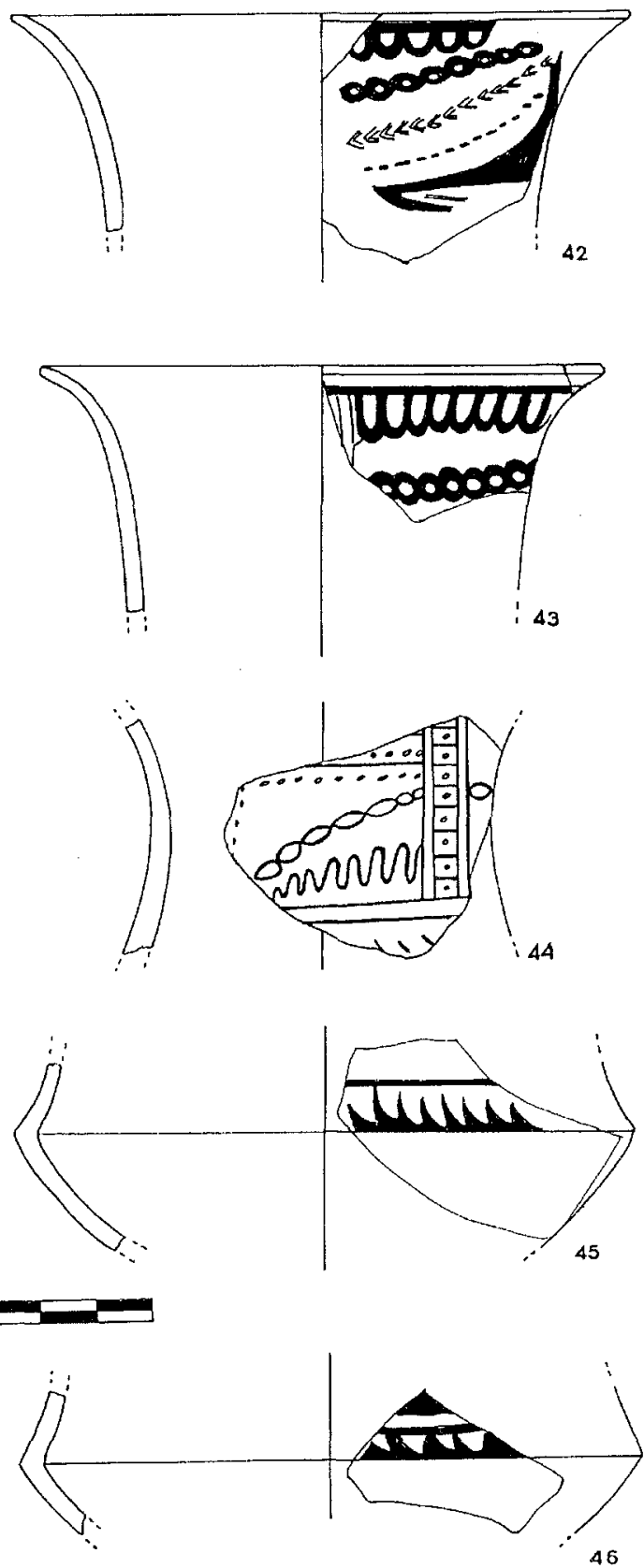

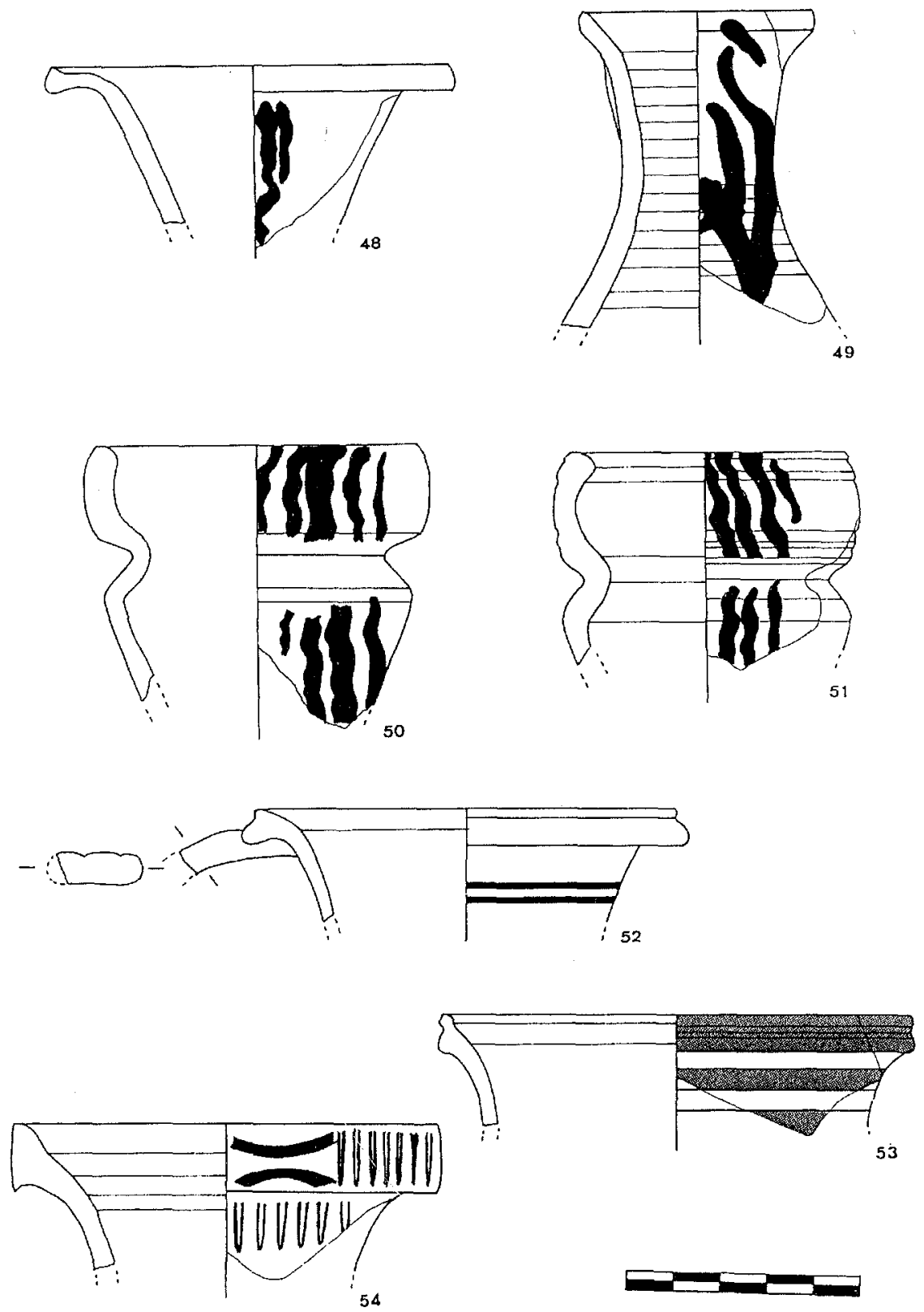
Cerámica pintada romana de tradición indígena procedente de Bilbilis
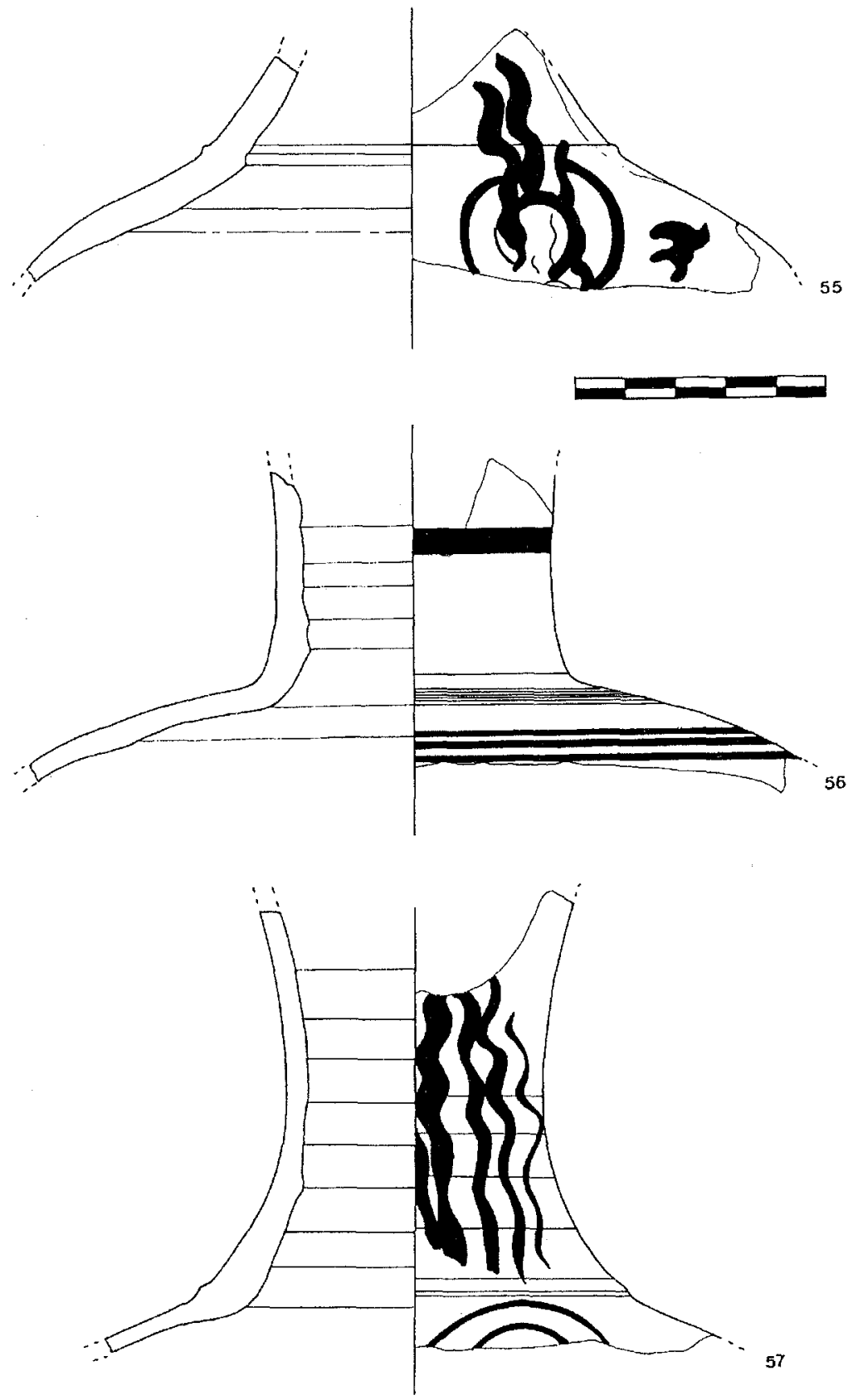

283 

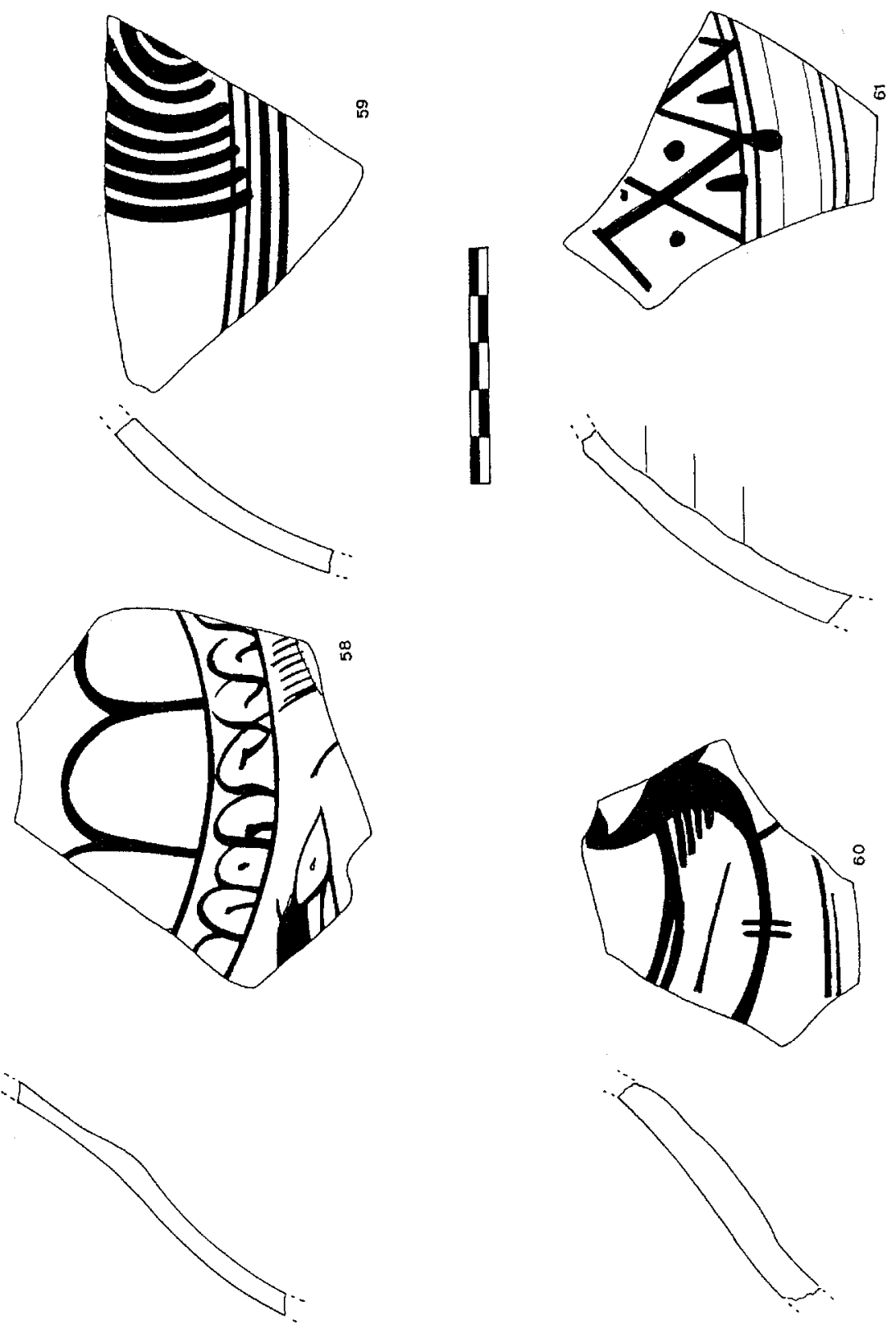

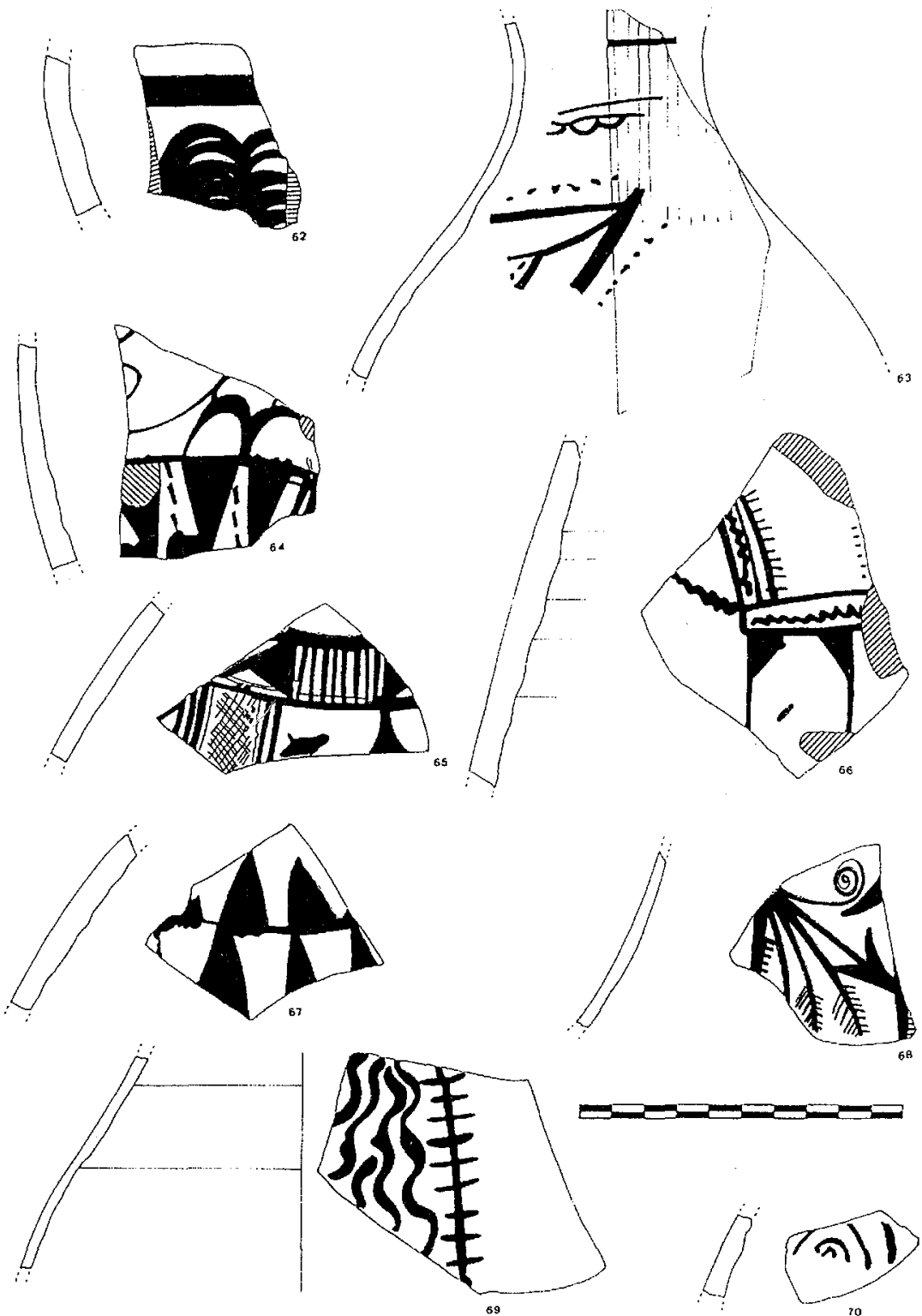

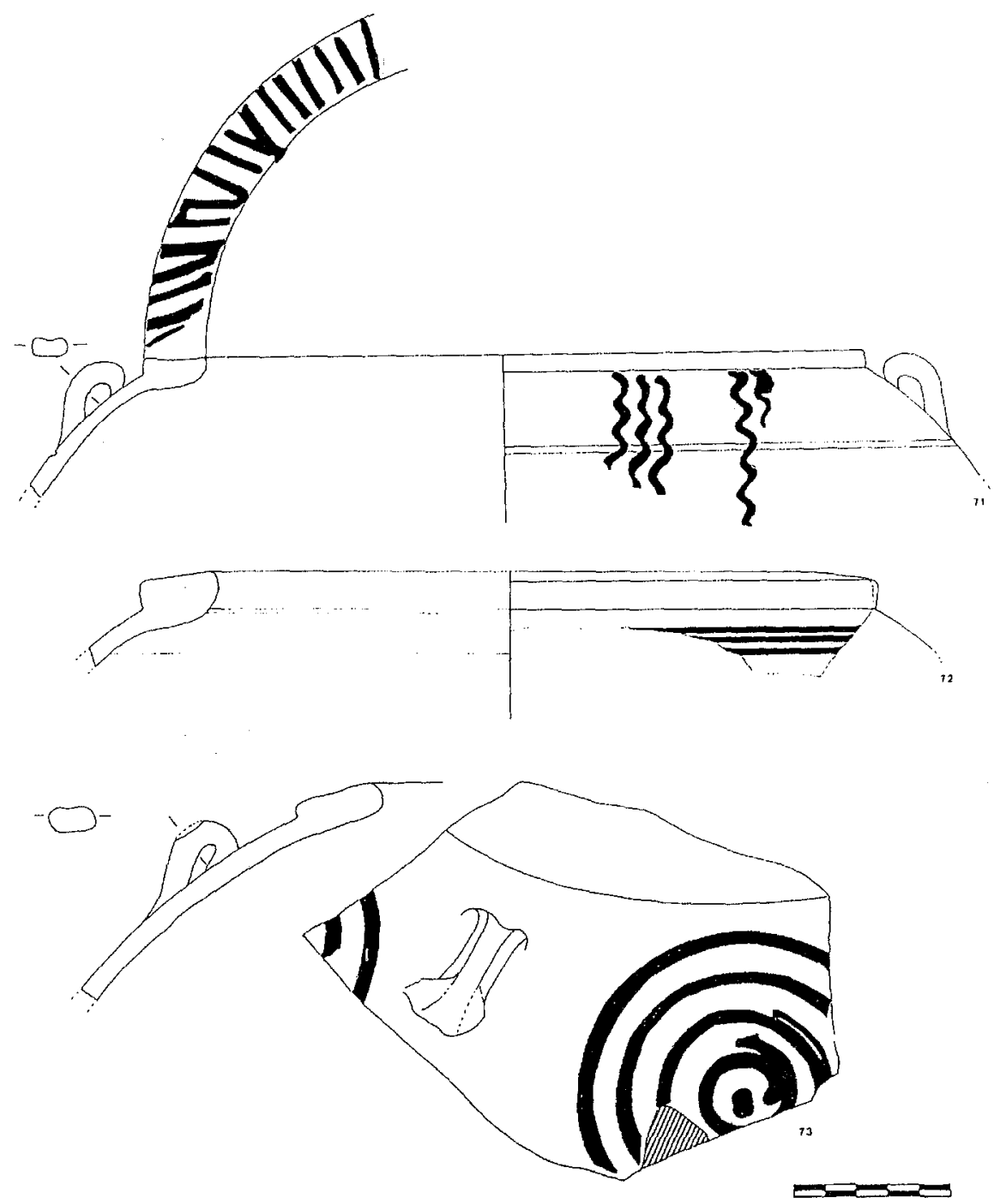

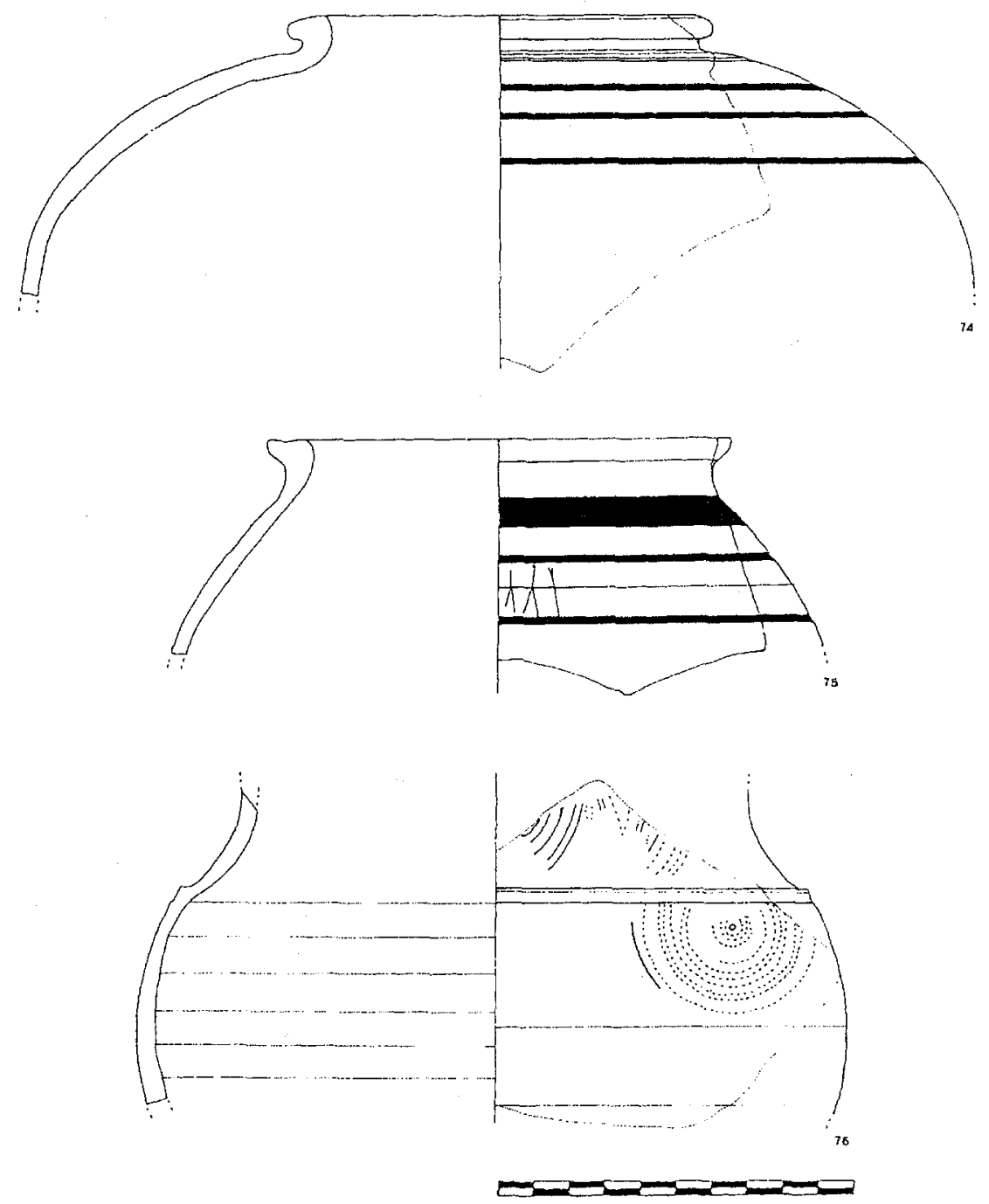

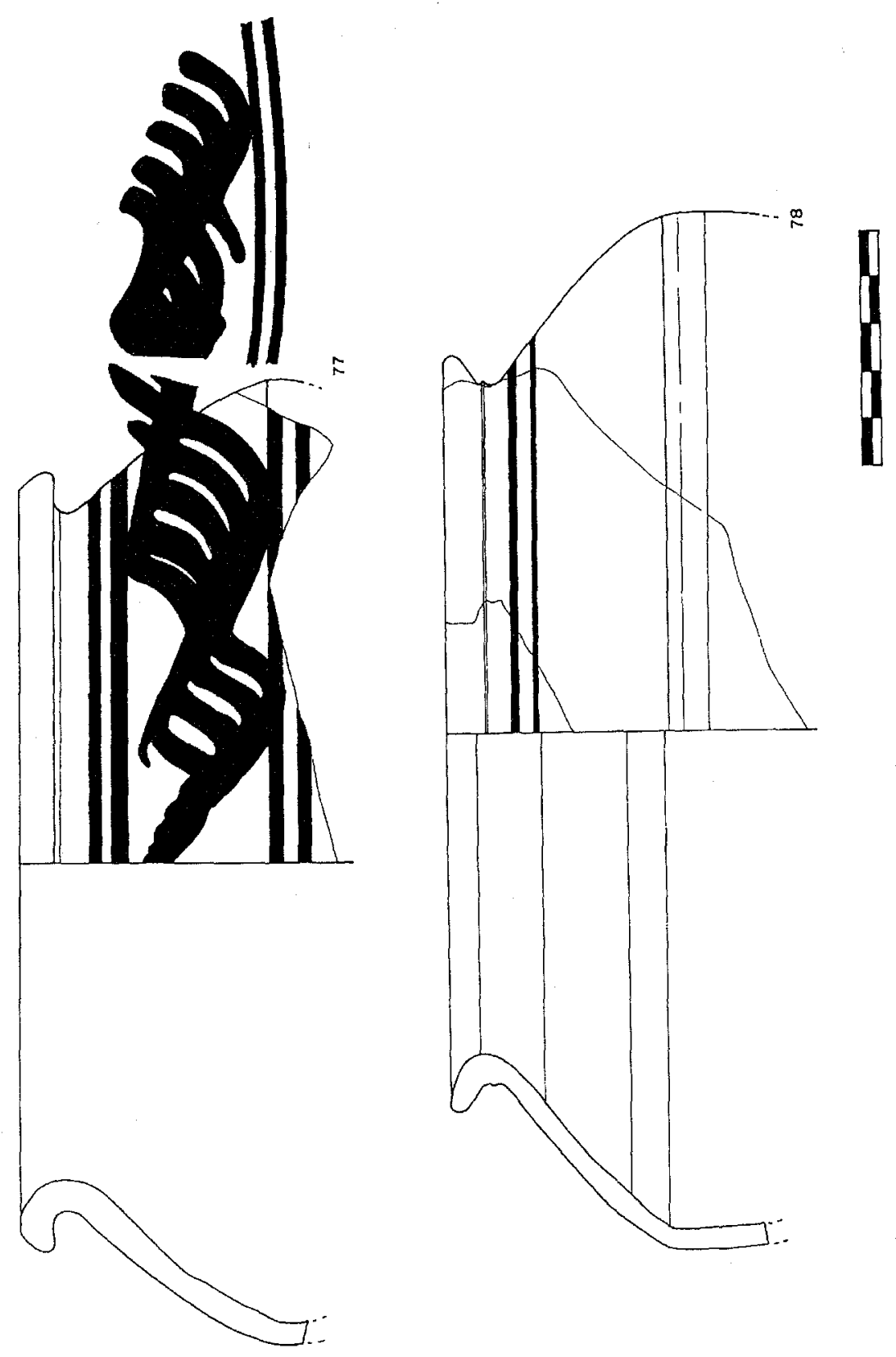

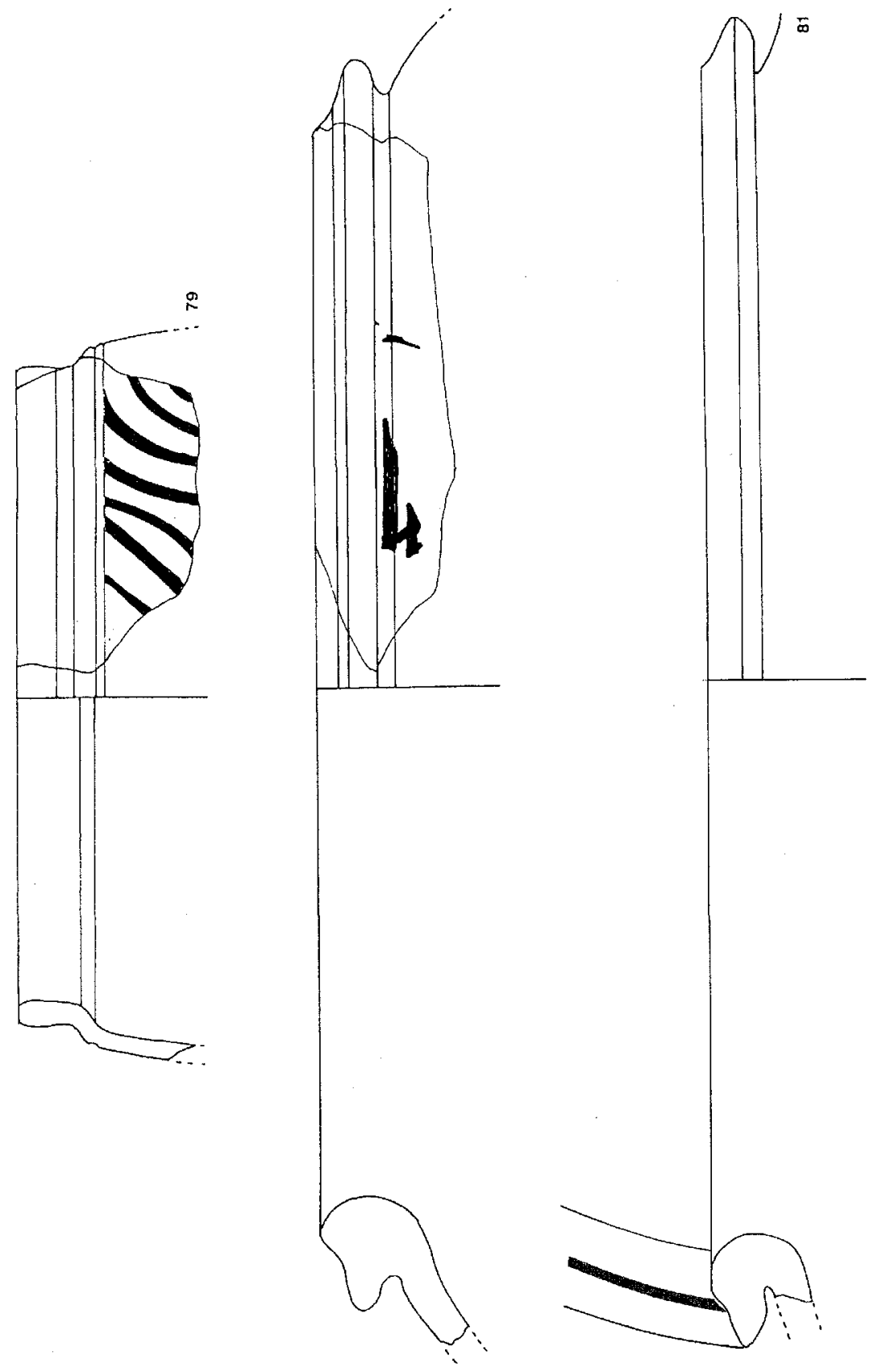

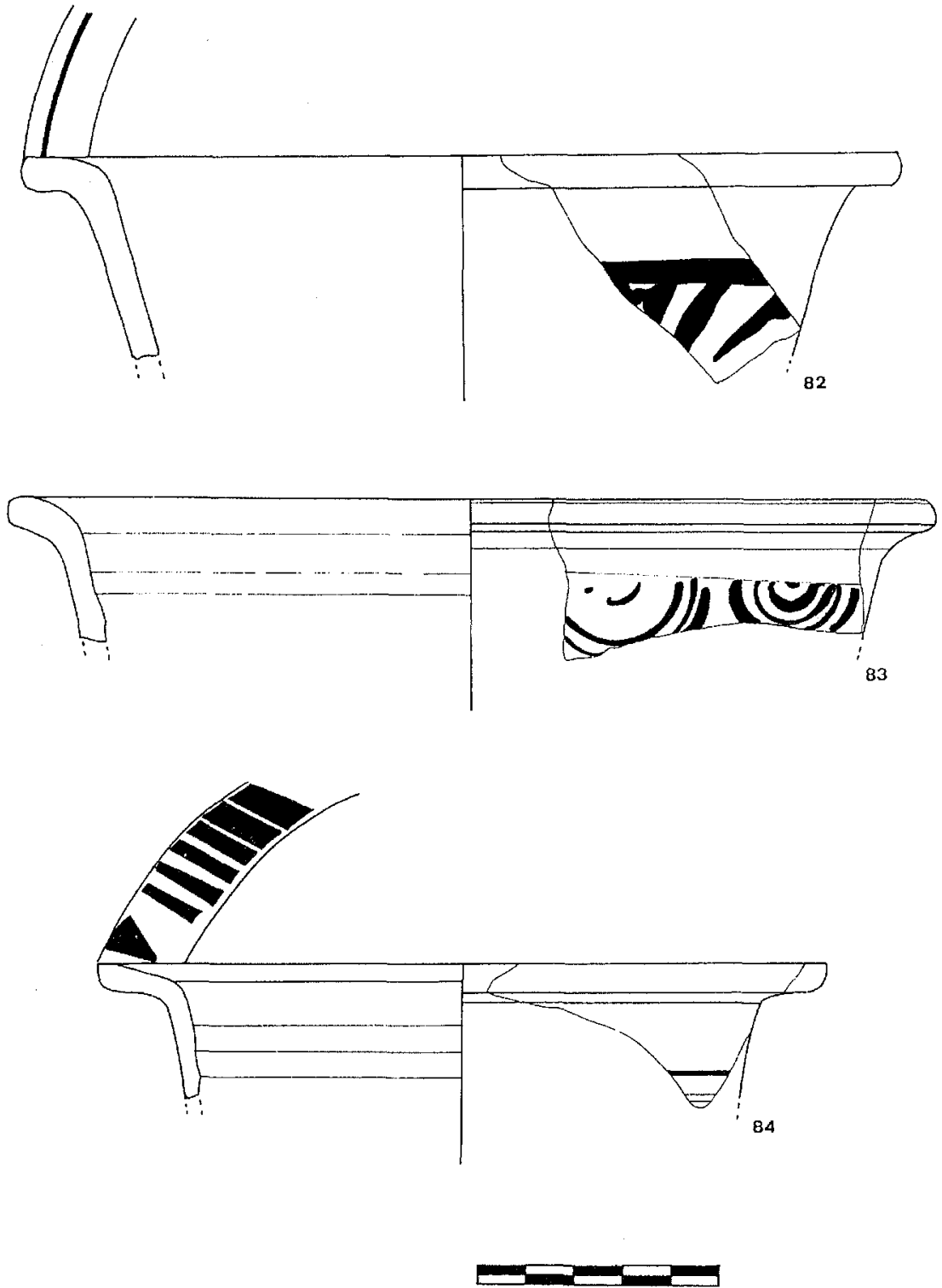


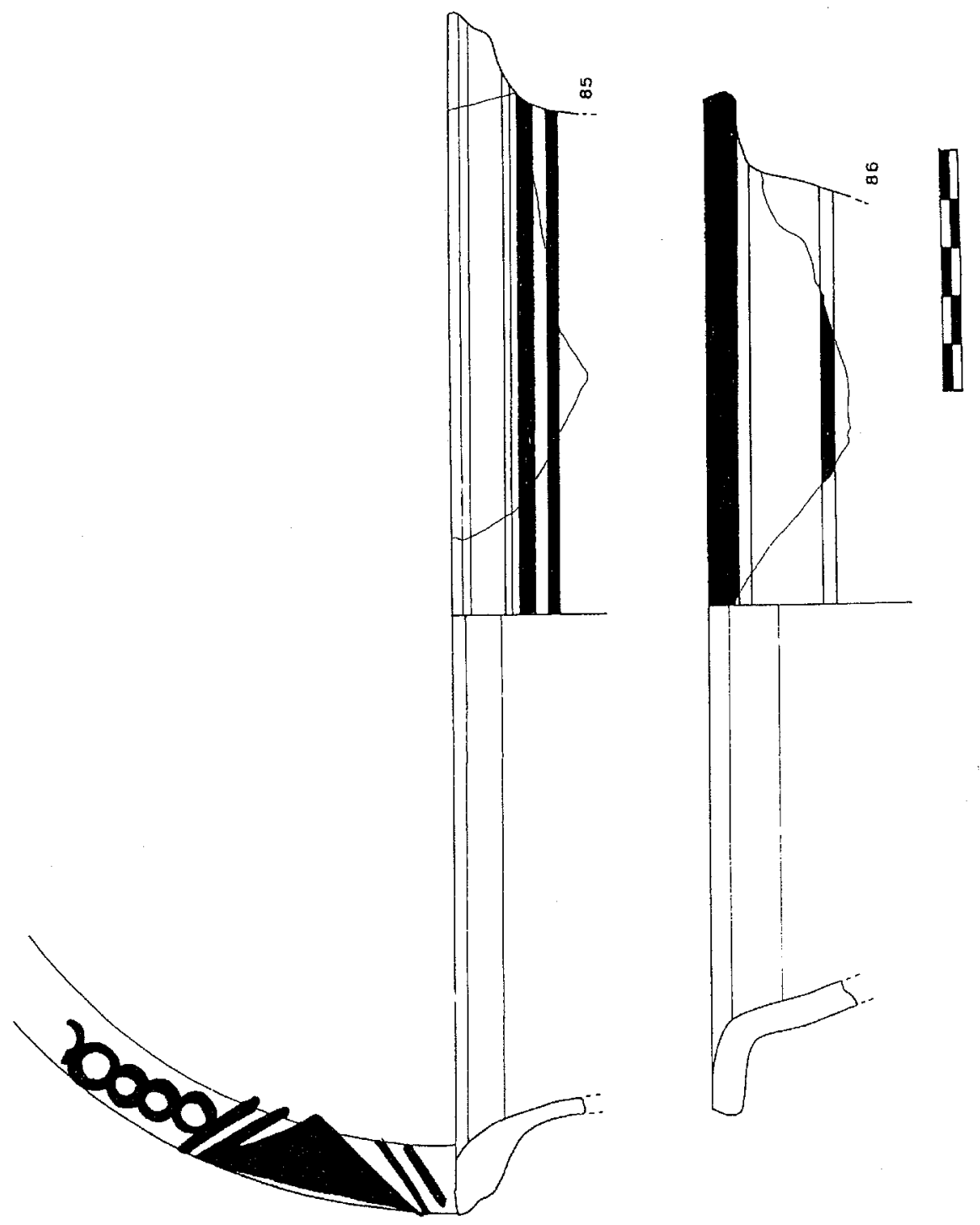



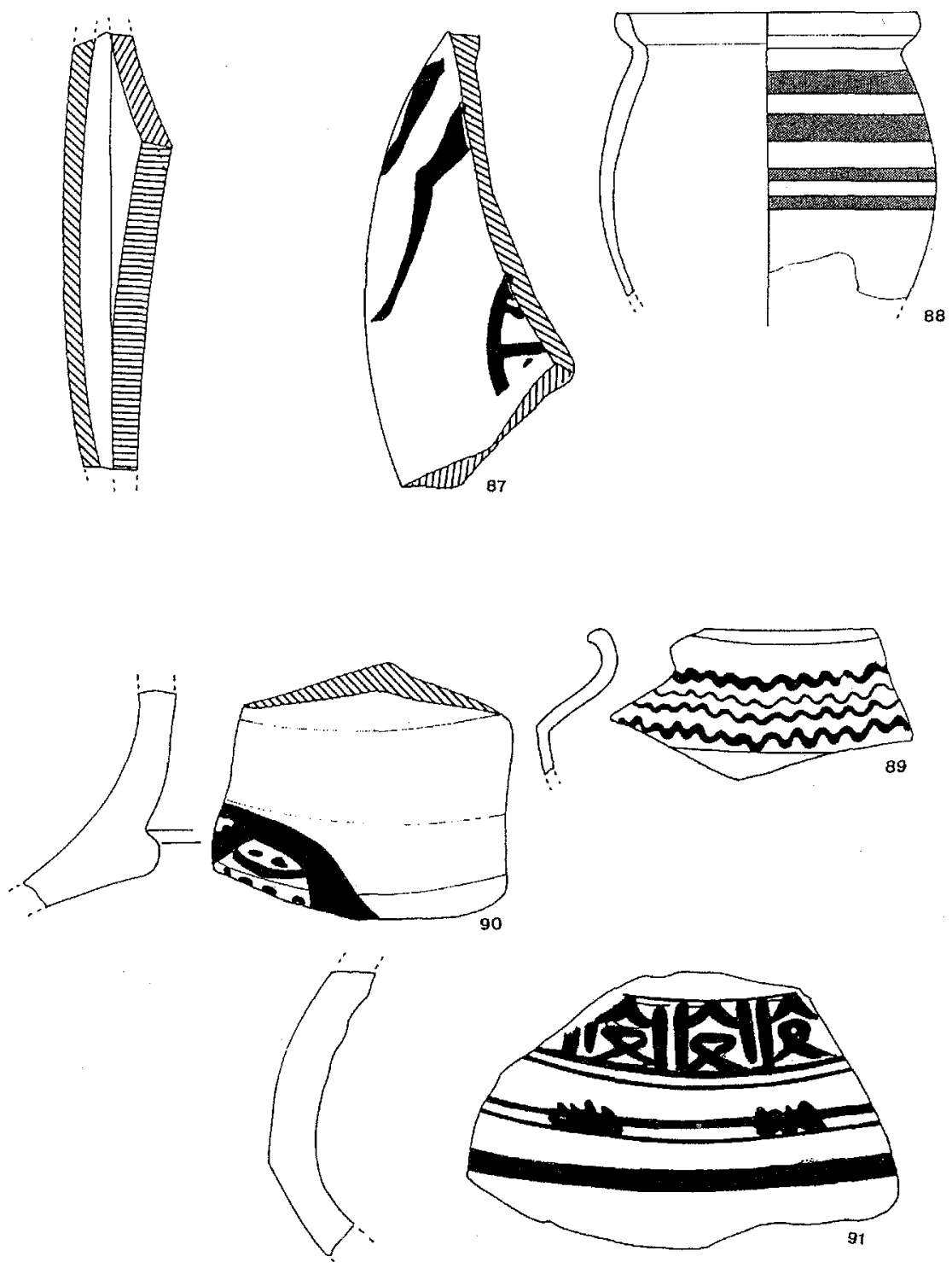

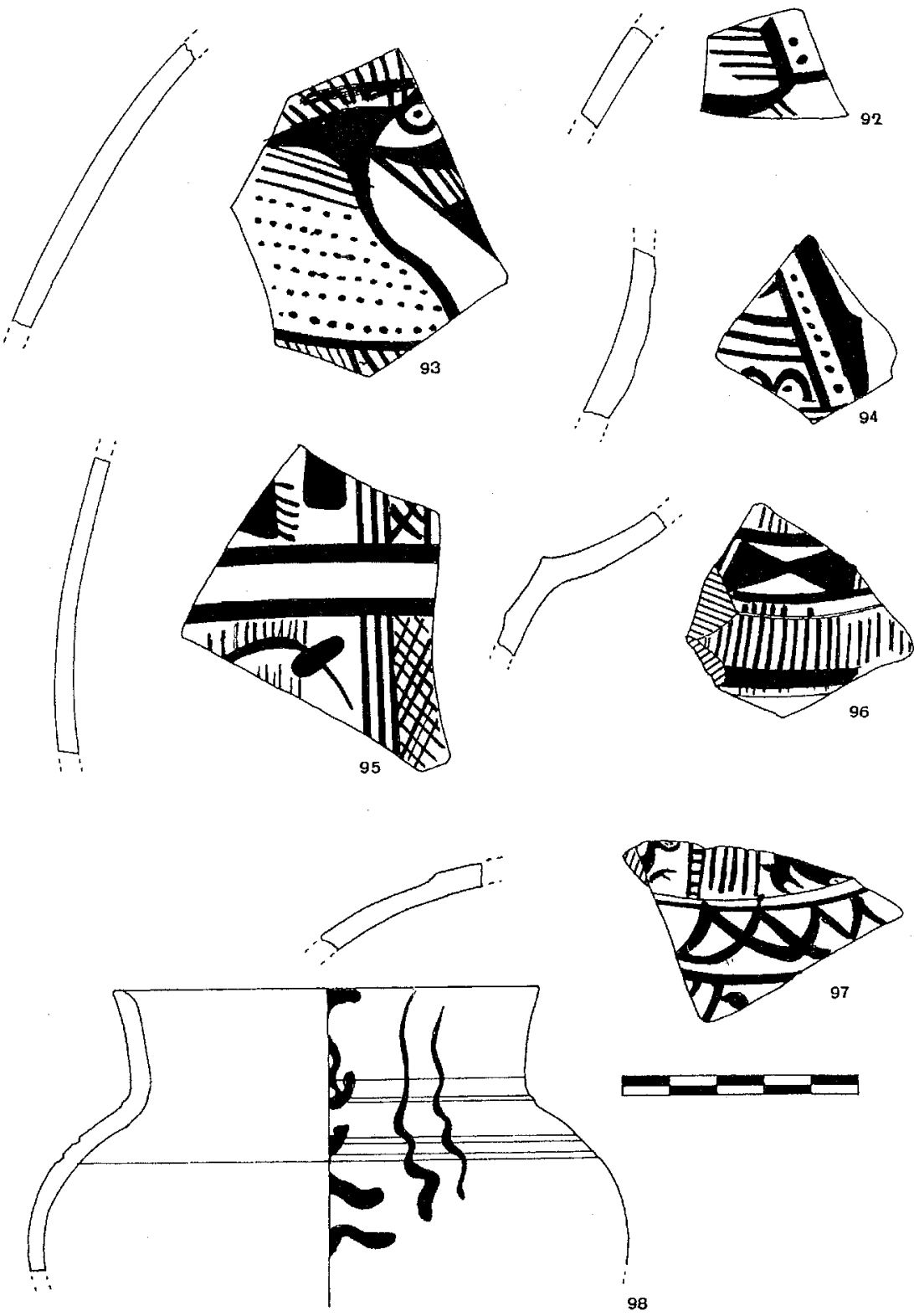